\section{A. ARS BILDUMA ISSN 1989-9262 UPV/EHU Press} ARSBILDUMA (CC BY-NC-ND 4.0)

https://doi.org/10.1387/ars-bilduma.21388 BIBLID [(2020), 10; 189-207]

Recibido: 10/01/2020 Aceptado: 28/02/2020

\section{JOSÉ JAVIER AZANZA LÓPEZ}

Universidad de Navarra

Dpto. de Historia, Historia del Arte y Geografía Edificio Ismael Sánchez Bella

Campus Universitario, s/n

31009 Pamplona (Navarra)

jazanza@unav.es

0000-0002-0375-7899

Grupo TriviUN.

\title{
OTEIZA Y LA ARQUITECTURA DESDE SU BIBLIOTECA: GAUDÍ, LA BAUHAUS, LE CORBUSIER
}

\author{
OTEIZA AND ARCHITECTURE FROM HIS LIBRARY: GAUDÍ, THE BAUHAUS, LE \\ CORBUSIER
}

\author{
OTEIZA ETA ARKITEKTURA BERE LIBURUTEGITIK: GAUDI，BAUHAUS，LE \\ CORBUSIER
}

\section{RESUMEN}

Entre los más de 6.000 volúmenes que componen la biblioteca personal de Jorge Oteiza custodiada en la Fundación Museo Jorge Oteiza (Alzuza, Navarra), alrededor de un centenar corresponde a textos relacionados con la arquitectura contemporánea, ámbito en el que el esculto vasco muestra particular interés por Gaudí y la Sagrada Familia, la escuela de la Bauhaus y Le Corbusier y el Modulor. Su estudio posibilita una aproximación directa al pensamiento oteiciano, quien concibe e libro como una eficaz herramienta a través de la cual dialoga con sus autores por medio de anotaciones y comentarios que ahondan en su proceso reflexivo y aportan claves de su propia obra.

PALABRAS CLAVE

Jorge Oteiza; biblioteca de artistas; arte de siglo XX; estética y teoría del arte; Antoni Gaudí; Bauhaus; Max Bill; Le Corbusier.

\section{ABSTRACT}

The private Library of Jorge Oteiza, located inside the Foundation Museum Jorge Oteiza (Alzuza, Navarra), is composed of more than 6,000 volumes, around a hundred of which correspond to texts related to Contemporary Architecture where the Basque sculptor shows a particular interest in Gaudí and the Sagrada Familia, the school of the Bauhaus and Le Corbusier and the Modulor. Their study makes possible a direct approach to the thought of the artist, who considers the book as an effective instrument through which he dialogues with their authors through annotations and comments that provide the keys to his own work.

\section{KEYWORDS}

Jorge Oteiza; library of artists; 20th Century art; aesthetics and art theory; Antoni Gaudí; Bauhaus; Max Bill; Le Corbusier

\section{LABURPENA}

Alzuzan, Nafarroan, Jorge Oteiza Museoaren Fundazioan dagoen Jorge Oteizaren liburutegi pertsonalak 6.000 liburutik gora gordetzen ditu. Haietako ehun inguru arkitektura garaikidearekin lotutako testuei dagozkie. Euska eskultoreak interes berezia erakusten Gaudi eta Sagrada Familia, Bauhaus eskola eta Le Corbusier eta Modulor gaietan. Liburutegiaren azterketak ahalbidetzen du Oteizaren pentsamendura hurbilketa zuzena egitea. Liburua tresna eraginkorra dela uste du Oteizak eta autoreekin hitz egiten du bere lanaren arrastoak eskaintzen dituzten oharpen eta iruzkinen bidez.

\section{GAKO-HITZAK}

Jorge Oteiza; artisten liburutegia; XX. mendeko arkitektura eta eskultura; artearen estetika eta teoria, Antoni Gaudi; Bauhaus eskola; Le Corbusier. 


\section{LA BIBLIOTECA PERSONAL DE JORGE OTEIZA}

Custodiada en la segunda planta de la Fundación-Museo Jorge Oteiza en Alzuza (Navarra), la biblioteca personal de Jorge Oteiza (Orio, Guipúzcoa, 1908-San Sebastián, 2003) está compuesta por un total de 6.012 documentos en la categoría de libros, registro del que quedan excluidos otros formatos y soportes, tales como revistas y folletos o archivos de vídeo y audio (Fig. 1$)^{1}$.

Tan ingente material, catalogado desde el año 2006, constituye una valiosa fuente de información para el estudio del escultor vasco, por cuanto su conocimiento va más allá del interés meramente bibliográfico. En efecto, no hablamos tan solo del inventario de libros, sino de la posibilidad de consultar los mismos ejemplares que tuvo en sus manos el artista; cuestión fundamental, por cuanto Oteiza -conviene recordar aquí su dimensión teórica- no se limita a su lectura, sino que los considera un instrumento útil en cuyas páginas anota multitud de comentarios e intercala textos personales en los que plasma sus opiniones, estableciendo así un diálogo vivo con los autores a los que en muchas ocasiones interpela o corrige a la hora de formular sus propias teorías. Todo ello posibilita una aproximación directa al genuino pensamiento oteiciano, como reconoce Borja González Riera, responsable del Centro de Documentación del Museo:

"Libros, folletos, revistas y prensa que pasaron por las manos de Jorge Oteiza a menudo presentan acotados, subrayados y comentarios de su puño y letra, y entre sus páginas se hallaron infinidad de papeles con anotaciones del escultor. Además de la relación de libros que componían su biblioteca, recurso tradicional en la historiografía sobre los artistas, los investigadores tienen aquí oportunidad de orientar y ampliar su conocimiento sobre lo que el artista pensaba en relación con el texto que leía en cada momento"2.

1. Deseo expresar mi agradecimiento a la Fundación Museo Jorge Oteiza de Alzuza en especial a su director Gregorio Díaz Ereño, y al responsable de su Centro de Documentación. Borja González Riera por la amabilidad con que atendieron mis consultas y por su ayuda en el acceso a las fuentes.

2 GONZÁLEZ RIERA, B.: "El centro de Estudios del Museo Oteiza: descripción y reflexiones de una andadura", Revisiones. Revista de crítica cultural, 7, 2011-2012, p. 210

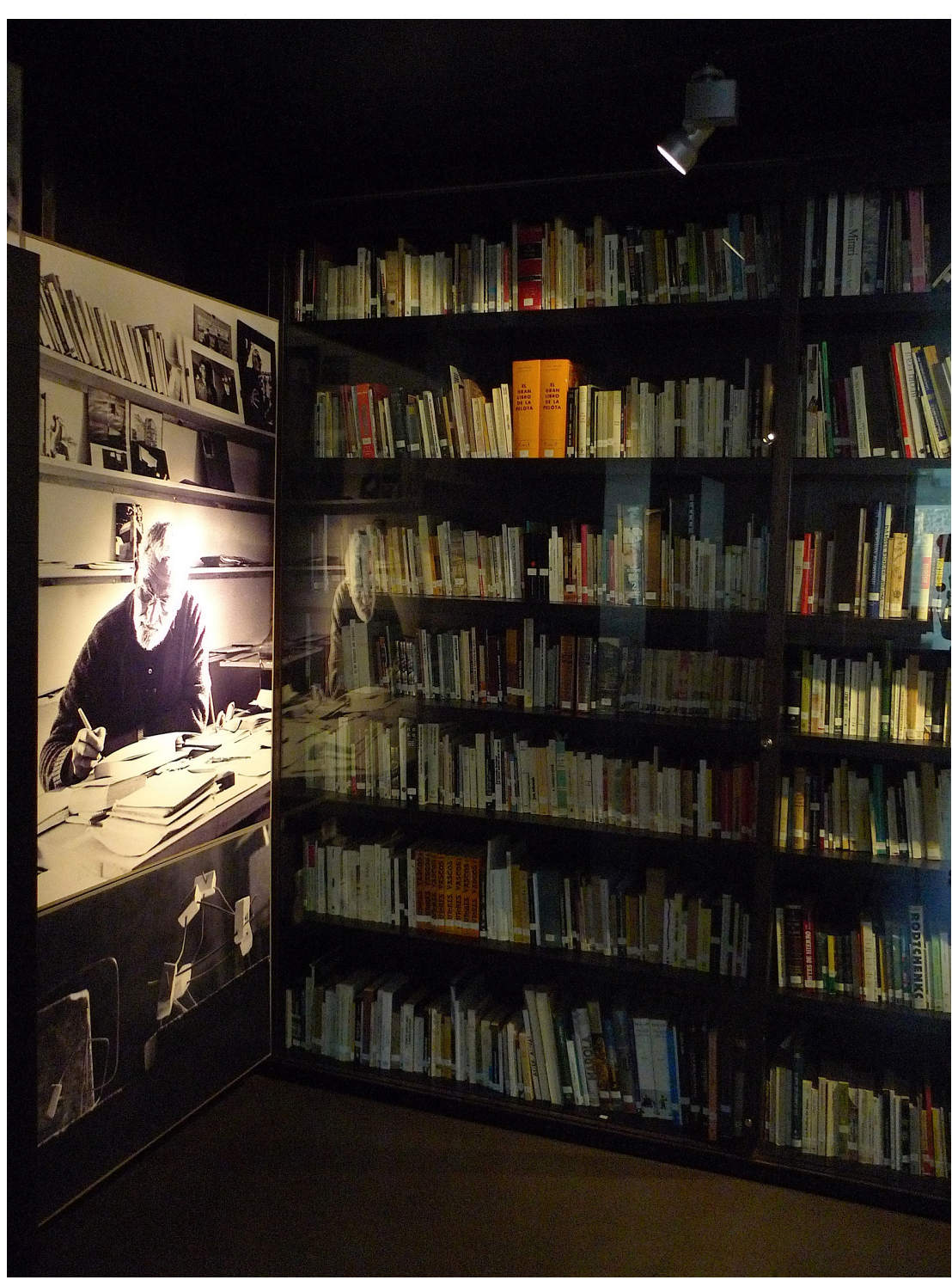

: Biblioteca personal de Jorge Oteiza, Fundación Museo Jorge Oteiza, Alzuza (Navarra). ๑ Jorge Oteiza () Pilar Oteiza, A+V Agencia de Creadores Visuales, 2020 
Tal idea había sido ya vislumbrada por Francisco Javier San Martín³ y en ella se reafirma posteriormente Emma López-Bahut, apuntando con acierto el concepto de diálogo:

"Se puede obtener mucha información del pensamiento de Oteiza del análisis de sus lecturas ya que trabajaba los textos subrayando, anotando, rebatiendo ideas expuestas en ellos, como si se tratase de un diálogo virtual con el autor"4.

La abundante -y en la mayoría de los casos inédita- información que proporciona el libro de la biblioteca oteiciana puede clasificarse en tres niveles, no necesariamente presentes en todos los volúmenes: la firma del artista -casi siempre OTEITZA- acompañada con frecuencia de la fecha y lugar de adquisición o de lectura del libro; los subrayados y comentarios al texto, que en ocasiones se reflejan en un índice personal elaborado por el artista al principio del libro con los temas y páginas de localización para facilitar su manejo; y la documentación anexa, de la que forman parte materiales de diversa naturaleza que el escultor introdujo entre las páginas del libro y que, en consecuencia, pasan a formar parte del mismo. Normalmente esta documentación guarda relación directa con el contenido del texto, tratándose de reflexiones que Oteiza lleva a cabo a partir de su lectura y en las que se extiende con mayor detalle; mas en otros casos se muestra independiente y tiene que ver con las propuestas plásticas que desarrollaba en aquel momento o con sus ideas sobre los más variados ámbitos -cultural, artístico, político, antropológico-, pero que por un motivo u otro decidió vincular al texto que estaba leyendo ${ }^{5}$

3 "En el caso de Jorge Oteiza, contamos con la ventaja de poder acceder a su biblioteca personal en la Fundación de Alzuza, lo que nos permite conocer no solo sus lecturas, sino las fechas desde las que disponí de ciertos libro ycatálog" SANMARTíN, F : "Oteiz

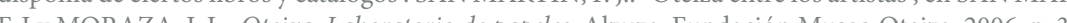

4 LÓPEZ-BAHUT, E.: Jorge Oteiza y lo arquitectónico. De la estatua-masa al espacio urbano (1948-1960) A Coruña y Alzuza, Universidade da Coruña y Fundación Museo Jorge Oteiza, 2015, p. 108. Así lo refrenda posteriormente la investigadora en un artículo en el que relaciona de manera precisa teorí y praxis: LÓPEZ-BAHUT, E.: "La lectura de Jorge Oteiza de Saber ver la Arquitectura a través de sus reflexiones dibujadas: influencia en sus trabajos arquitectónicos”, EGA. Revista de expresión gráfica arquitectónica, 21, 28, 2016, pp. 114-125.

5 Sobre estos y otros aspectos en relación con la biblioteca de Oteiza reflexiona AZANZA LÓPEZ, J. J. "Tratados, fuentes y textos teóricos del arte contemporáneo en la biblioteca personal del escultor Jorge Oteiza”, en ALONSO RUIZ, B., GÓMEZ MARTÍNEZ, J., POLO SÁNCHEZ, J. J., SAZATORNIL RUIZ, L. y VILLASEÑOR SEBASTIÁN, F. (eds.): La formación artística: creadores, historiadores, espectadores, Vol. 2. Santander, Universidad de Cantabria, 2018, pp. 1303-1316.
Esta rápida aproximación a la biblioteca personal de Oteiza nos pone en disposición de abordar el tema objeto de estudio, para el que hemos seleccionado un conjunto de arquitectos de la primera mitad del siglo XX a los que presta particular atención, en un recorrido que transita del modernismo de Gaudí al funcionalismo de Le Corbusier, con un paso intermedio por la escuela de la Bauhaus. No son, ciertamente, las únicas corrientes con las que el escultor se relaciona a través de sus lecturas, dado que una visión más amplia nos descubre su interés por las huellas del racionalismo en España, los ecos de la Secesión vienesa y los arquitectos de la posmodernidad, entre otros. Pero sí son, quizás, los arquitectos que determinaron en mayor medida su propuesta estética en un momento trascendental para Oteiza como fue la década de 1950.

A través de este breve recorrido conoceremos algunas claves que guiaron el pensamiento estético del escultor vasco; no en vano, su interés por la arquitectura, que entendía como resultado de la conjunción de todos los lenguajes artísticos ${ }^{6}$, unida a la indagación espacial desarrollada a través de la escultura y a su concepto totalizador del arte, favorecieron la implicación activa del escultor en sucesivos proyectos arquitectónicos no como mero observador, sino como activo creador $^{7}$. No pretendemos, obviamente, abordar las ideas de Oteiza con afán totalizador, sino aportar algunas reflexiones que el escultor plasmó en las páginas de los libros que consultó, con el propósito de contribuir al rico debate generado en torno a las mismas.

"El sentimiento del hombre en la arquitectura está en el ingreso al sentimiento artístico de todas las expresiones comparadas". OTEIZA, J.: "Estética del huevo. Mentalidad vasca y laberinto", en FULLAONDO, J. D. (ed.): Oteiza, 1933-1968. Madrid, Nueva Forma-Alfaguara, 1968, p. 87

7 Representativa de tan estrecha vinculación será la exposición Oteiza y la arquitectura: múltiple reflejo (1996), que comprendía diez proyectos en los que el escultor participó entre 1952 y 1989, con el objetivo de desvelar "la especial vinculación de Oteiza con el mundo de la arquitectura a través de sus relaciones con el arte, la filosofía y la religión", en palabras de los comisarios C. Lapagesse y D. Gazapo. Oteiza le arquitectura múltiple reflejo, Pamplona Pamiela, 1996. La relación Oteiza-arquitectura ya hár sido chectura: multiple observada en un fecha temprana por el arquitecto Rafacl Mone, como qued NEO VALLES, R.. "Jorge de Oteiza, arquitecto, Nueva Forma, 16, 1967, pp. 22-23. Varias tesis doctorales han abordado en los últimos años la relación entre Oteiza y la arquitectura, caso de F. Moral (Oteiza, arquitectura como desocupación espacial, Universitat Politècnica de Catalunya, Barcelona, 2007); R. Mena (Oteiza-Newman-Mies van der Rohe: espacios compartidos. Una hermenéutica de la desocupación del espacio en escultura, pintura y arquitectura, Universitat Pompeu Fabra, Barcelona, 2012); I. Remen teria (Proyecto no concluido para la Alhóndiga de Bilbao. Una propuesta sobre la estética de Jorge Oteiza como método de investigación Universidad del País Vasco, 2012). I. E. Ramos (El espacio activo de Jorge Oteiza Universidad de Valladolid 2014, que ha da lo lugar allibo Hoyo a Oteizaci Unice espaciales en Jorge Otiza, Alzuza, Fundación Museo jorge Oteiza, 2018), y A. T. Marin (Pulsiones del es pacio. Oteiza y la aproximación a la arquitectura como vacío activo, Universidad Politécnica de Madrid, 2015), además de la ya citada de E. López Bahut (Universidade da Coruña, 2013). 
Recogemos en todos los casos, entre paréntesis y a continuación del título, la edición conservada en la biblioteca y que en consecuencia manejó personalmente el escultor guipuzcoano, acompañada de su número de registro $(\mathrm{FB})$ y signatura (Sign.), para facilitar así a los investigadores su localización y consulta.

\section{GAUDÍ Y LA SAGRADA FAMILIA: UN ROBO CONFESO DECISIVO} PARA LA ESTÉTICA OTEICIANA

En Conversaciones con Gaudí (Punto Fijo, Barcelona, 1969, FB-3443, Sign. 3216), el arquitecto ilerdense César Martinell evoca los diálogos que mantuvo con su maestro Antoni Gaudí, plasmando la esencia de la doctrina gaudiana, sobre todo en relación con el Templo de la Sagrada Familia. Recordemos a este respecto que Oteiza siempre manifestó su admiración por el arquitecto catalán y que conoció su taller en la Sagrada Familia, experiencia que le marcó al descubrir en él el misterio de lo inmóvil ${ }^{8}$.

De los continuos subrayados que Oteiza introduce en el libro se deduce que dos son los temas por los que se interesa particularmente: las superficies alabeadas y el paraboloide hiperbólico. Acerca del primero, los comentarios del arquitecto le llevan a considerar la superficie alabeada como "superficie continua y polivalencial o tridimensional", por cuanto al generarse a partir de una línea curva no se puede superponer sobre un plano (p. 54) siguiendo con la reflexión de que las formas continuas son las perfectas y de que incluso las planas pasan con el tiempo a ser alabeadas, el escultor se pregunta qué ocurriría "si un plano de $\mathrm{P}$ (iet) M(ondrian) sufriera una torsión, un alabeo" (p. 55). Pregunta difícil de responder, por cuanto Mondrian, "pintor a quien he admirado siempre por su tenacidad experimental", reconoce Oteiza ${ }^{10}$, pero al que recrimina no haber sabido aprovechar sus

8 El diálogo entre Oteiza y Gaudí se reactivó en la exposición Oteiza. La desocupación del espacio, celebrada entre septiembre de 2016 y enero de 2017 en la Fundació Catalunya-La Pedrera.

9 Oteiza abunda en su reflexión sobre la superficie alabeada aplicada a la arquitectura y escultura (con referencias a Gaudí y van Doesburg) en "La solución alabead", sl. s. f. Archivo dela Fundación Museo Jorge Oteiz (en adeante AFMJO), FD-9003. Este documento se hallaba intercalado entre las paginas del libro de PLAZAOLA, J.: El arte y el hombre de hoy: apuntes para una filosofía del arte contemporáneo. Valladolid, Diputación Provincial de Valladolid, 1978 (FB-5497, Sign. 5319).

10 "Mi encuentro con Piet Mondrian", s.l., s.f. AFMJO, FD-3213. hallazgos, elimina de la composición pictórica cualquier elemento curvo ${ }^{11}$. El escultor ya se había interesado por esta cuestión a finales de los años cincuenta, cuando materializó el concepto espacial ortogonal de Mondrian en Unidades rectas cerradas en orden dinámico y rectilíneo (recuerdo para Mondrian) y Desocupación de la esfera. Conclusión para Mondrian ${ }^{12}$.

En cuanto al segundo asunto de interés oteiciano, el paraboloide hiperbólico, confiesa propósito de su empleo por Gaudí en las bóvedas de la Colonia Güell y de la Sagrada Familia que ahí se encuentra la fuente de inspiración de su hiperboloide, que el escultor vasco define como "el cilindro abierto al exterior, puesto en una cuarta dimensión plástica"13. Nos retrotrae así a sus investigaciones de comienzos de la década de 1950, cuando sustituye el cilindro cezanniano por un nuevo modelo geométrico con mayor capacidad de apertura e interacción como es el hiperboloide, que vendría a ser una especie de cilindro con sus paredes rehundidas frente a la idea de un nuevo cilindro obtenido por perforación, característico de la plástica de Henri Moore o Barbara Hepworth ${ }^{14}$.

El hiperboloide conduce al escultor oriotarra a una nueva realidad espacial que lo pone en disposición de desarrollar un planteamiento puramente abstracto de la escultura en detrimento de lo figurativo, si bien la ejecución de la estatuaria del santuario de Aranzazu (Guipúzcoa) ralentizará dicho proceso ${ }^{15}$. Oteiza se declara "culpable" del hurto a Gaudí, antes de lanzar un exabrupto colectivo que luego individualiza, aunque sin concretar el destinatario (Fig. 2):

"1 sola vez he robado en mi vida, y lo he devuelto: el hiperboloide de Gaudí (como he sido yo despojado y nadie me ha devuelto nada, ni esculturas ni escritos), malditos sean los que sabéis que sois, malditos y desgraciados, sinvergüenza y cínico, maldito seas” (p. 55)

SAN MARTIN, F. J. y MORAZA J. L.: op. cit., pp. 110-113.

12 BADIOLA, TX.: Oteiza. Catálogo razonado de escultura. Alzuza, Fundación Museo Jorge Oteiza, p. 488

13 "Memoria: escultor Jorge Oteiza. Proyecto de monumento al político cautivo desconocido. Maqueta: Prometeo múltiple”, s.l., 1951. AFMJO, FD-15381. Ya Carlos Martínez Gorriarán recuerda la relación entre Oteizz Gavd a propósito del empleo del hiperboloide por este ́́ltimo- MARTÍNEZ GORRIARÁN, C.: Jorge Oteiza, hacedor de vacíos. Madrid, Marcial Pons Historia, 2011, p. 177.

14 Nuevas opiniones vierte el escultor vasco sobre este asunto en "Cilindro e hiperboloide", s.l. s.f. AFMJO FD-3235; y "H. Moore y la escultura moderna", s.l., s.f. AMFJO, FD-15726

15 BADIOLA, TX.: op. cit., p. 416 


\section{ORIGINAL A PESAR SUYO 5}

son sostenidos y sustentantes. Esta distinción crea el punto imperfecto, que nace de la solución de continuidad al pasar del elemento que se de las jambas al dintel, se pone algún ornamento (capiteles, impostas, car. telas), a fin de distraer la atención de aquel lugar, resuelto defectuosamente. Se cubre una deficiencia de concepto con un detalle agradable la vista y se desvía la cuestión del campo estructural al decorativo.

Las formas poliedricas y las llamadas geométricas con erróneo excluivismo abundan poco en la Naturaleza. Inluso aquellas que el hombre hace planas (puertas, mesas, tableros) con el tiempo pasan a ser ala-

\section{La originalidad}

Razona sus ideas estructurales y estéticas y dice que son de una lógica dindisputable» (siempre utiliza esta palabra, nunca, "indiscutible». Le da mucho que pensar el que no se aplicasen antes y que él tenga que dudar ponen La estructura que tendrá la Sagrada Famili 10 emplo Colonia Güell. Sin este previo ensayo no se hubiese atrevido a adoptarla para el Templo.

Diciembre de 1949

$$
9^{\circ}-
$$

Al revisar estos apuntes para su publicación, vuelvo a darme cuenta de que algunos temas que fueron objeto de conversación escaparon a la anotación sistemática. Estas omisiones no fueron muchas y coinciden con cionadas con la breve fueron objeto de publicaciones periodísticas relacindo del orden cronológico preestablecido y a continuación anoto lo que recuerdo $y$ aquello que publiqué en fechas posteriores, referido a cuestión, tan traída y llevada, de la originalidad del arquitecto.

Un cimborio del Templo inspirado en una obra del escultor Bonifòs

Fue a principios del año 1921 cuando me interesó conocer la opinión e Gaudí sobre las cualidades de la obra del escultor Luis Bonifàs Massó, que yo estudiaba entonces. Con este propósito, llevé a las oficina

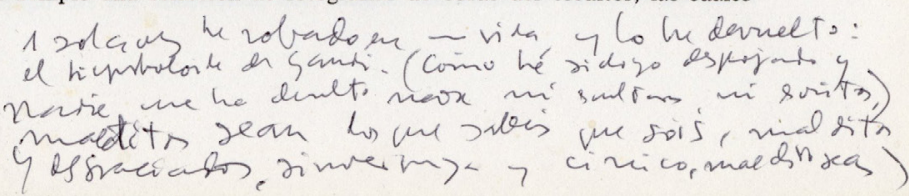

Fig. 2: César Martinell, Conversaciones con Gaudí. Anotación personal de Jorge Oteiza. AFMJO, FB-3443, Sign. 3216 @ Jorge Oteiza ๑ Pilar Oteiza, A+V Agencia de Creadores Visuales, 2020
No sería muy arriesgado identificar el blanco de sus iras con el escultor donostiarra Eduardo Chillida, de quien decía que "su Biblia ha sido el orientalismo mandálico de Palazuelo y luego mi pensamiento publicado y mi obra"16. Mas con independencia de la denuncia (recordemos a este respecto su Libro de los plagios) ${ }^{17}$, resulta de gran interés constatar cómo, en palabras del propio Oteiza, en la arquitectura gaudiana se encuentra la base de su propuesta abstracta, asomándonos por tanto a un nuevo ejemplo de la relación Oteiza-arquitectura.

Realiza además su propia intersección de un hiperboloide con un plano de luz (p. 41), y no le pasa desapercibido el hecho de que en el templo barcelonés la geometría de las campanas sea únicamente hiperbólica, carente del casquete esferoidal superior, mostrando por tanto una forma tubular y no cilíndrica (p. 61).

Resulta muy jugoso el comentario a la Fachada del Nacimiento de la Sagrada Familia (Fig.

3), en la que reconoce una nueva deuda con el arquitecto catalán:

"Es un bosque invertido. Los árboles crecen hacia abajo, suben invertidos e hincados en la tierra. Vuelven a subir, ascensores en helicoide [...] Lo emocionante, para mí, es una extensión mínima de columna que uno cree ha quedado quieta y ver cómo un movimiento imperceptible la anima. Para mí este fragmento sería mi escultura ideal. Algo de este despertar del movimiento en una columna fue mi proyecto de Prometeo para Londres (ver si los cambio por las hipérbolas de Gaudí) (s.p.)".

Asistimos, por tanto, a partir del dinamismo que generan los elementos estructurales de la fachada gaudiana, a la relación entre esta y Prometeo, propuesta desarrollada en torno a la configuración del vacío como expresión plástica de su nuevo concepto del universo y del hombre espiritual con la que concurrió Oteiza al concurso internacional del Monumento al

16 "Chillida y Maruja Mallo", s.l., s.f. AFMJO, FD-6818

17 OTEIZA, J.: Libro de los plagios. Pamplona, Pamiela, 1991. En su tesis doctoral que aborda la figura de Chillida como arquitecto, Beatriz Matos matiza esta percepción al afirmar que "las cosas no son tan sencillas como las presenta Jorge Oteiza, en el momento de máximo conflicto con Chillida, en el Libro los Plagios, basándose en los, en muchas ocasiones, evidentes parecidos formales entre obras de ambos o con otros autores" para concluir: "brillante intelectual, Jorge Oteiza abrió algunos caminos por los que Chillida transitó, haciéndolos inmediatamente propios y reinventándolos desde su enorme y poética capacidad escultórica". MATOS CASTAÑO, B.: Eduardo Chillida, arquitecto. Madrid, Universidad Politécnica de Madrid, 2015, p. 21 


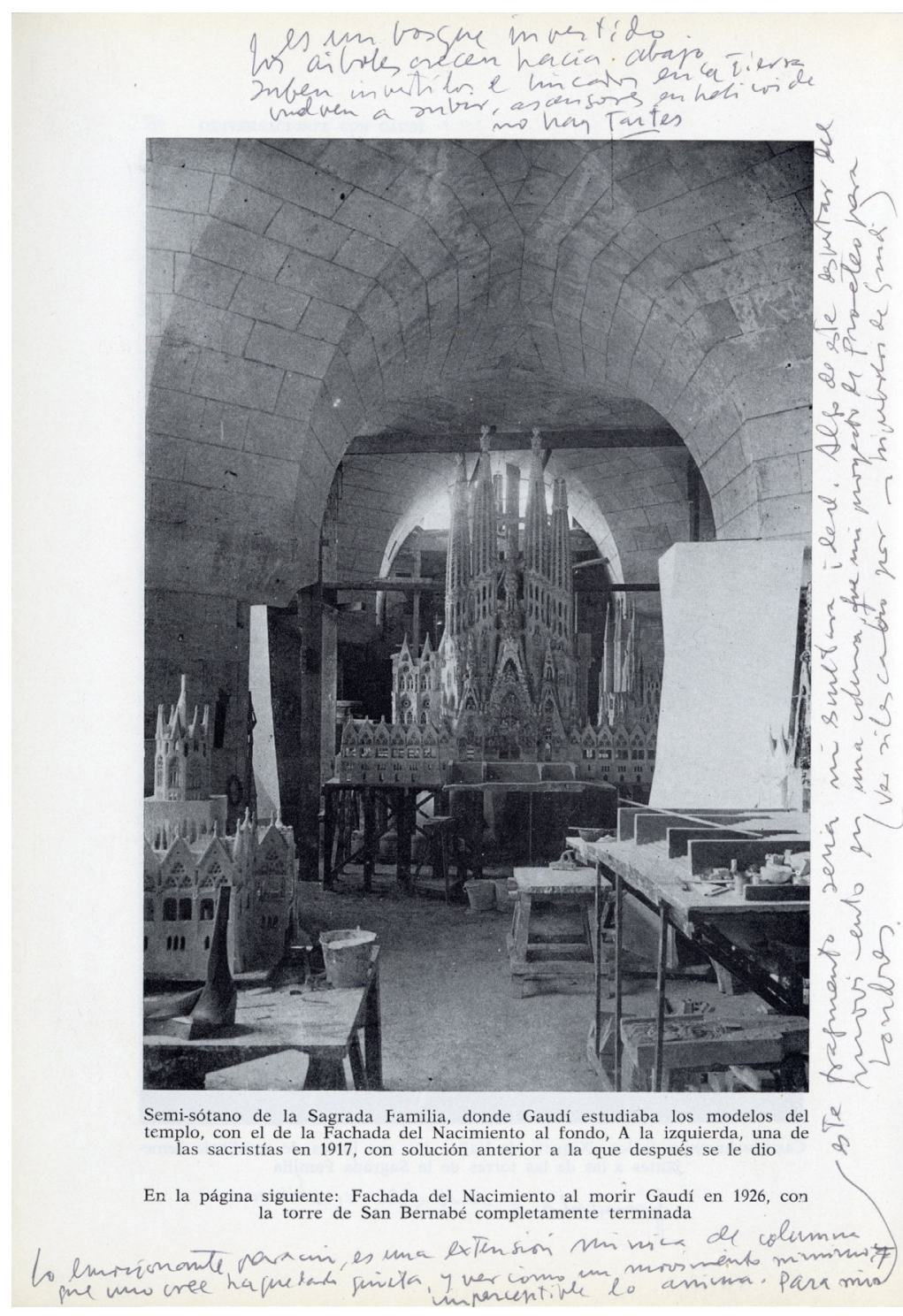

Fig. 3: César Martinell, Conversaciones con Gaudí. Anotación personal de Jorge Oteiza. AFMJO, FB3443, Sign. $3216 \odot$ Jorge Oteiza @ Pilar Oteiza, A+V Agencia de Creadores Visuales, 2020 prisionero político desconocido, convocado por el Institute of Contemporary Art de Londres en 1952. El imperceptible movimiento de la columna al que se refiere viene proporcionado por el hecho de que las dos columnas verticales separadas que, junto con una tercera abatida, configuraban su proyecto, quedaban moldeadas internamente por hiperboloides, creando en consecuencia un espacio vacío hiperbólico cuya irregularidad superaba la tradicional rigidez intercolumnaria ${ }^{18}$

El concepto gaudiano de parábola invertida ("la colgadura invertida de Gaudî") hará de nuevo acto de presencia en algunos documentos de la década de 1980 relacionados con el proyecto de centro cultural en la Alhóndiga de Bilbao, para el cual realiza una maqueta a partir de tizas que toma como referencia las parábolas del arquitecto catalán ${ }^{19}$.

La atrae asimismo la "calderería" de Gaudí, el dominio de la metalurgia, en el sentido de que posee la cualidad de ver el espacio por haber sido hijo, nieto y bisnieto de caldereros, profesión que abarca las tres dimensiones al crear un volumen a partir de una plancha; de hecho, el arquitecto catalán consideraba clave el proceso de la calderería para su capacidad de materializar sus ideas arquitectónicas ${ }^{20}$, de ahí el rechazo a dos discípulos suyos "porque les falta la calderería [...] el espacio es calderería". Oteiza reconoce: "igual diría yo de mis discípulos de DEVA" (p. 98), en referencia a la Escuela Experimental de Arte de Deba (Guipúzcoa), proyecto educativo encaminado a la creación de un Centro de Estética Comparada que puso en marcha en 1969 con el propósito de "marcar rumbos desde lo vasco", si bien no fue entendido de la misma manera por todos sus integrantes, lo cual llevaría al escultor a afirmar apenas tres años más tarde que "me siento enfermo con

18 En su versión final de 1965 , el monumento consiste en dos columnas en paralelo erosionadas en función de la aplicación del vaciado material mediante el hiperboloide. Significa TX. Badiola sobre esta obra que, mediante la creación de un espacio vacío hiperbólico por la conjunción de las dos columnas moldeadas internamente por hiperboloides, Oteiza avanza del "viejo cilindro" de Cézanne al "nuevo cilindro abierto" contemporáneo; con todo, y pese a realizarse desde un posicionamiento abstracto, la propuesta del escultor guipuzcoano no entra a valorar la capacidad de la figuración y abstracción como vehículo trasmisor de ciertos valores. BADIOLA, TX.: op. cit., pp. 410-411 y 422-424. Puede consultarse también al respecto AGUIRRE MARTÍNEZ, G.: "Prometeo de Oteiza, un modelo para la desocupación espacial”, Ars Bilduma. Revista del Departamento de Historia del Arte y Música de la Universidad del País Vasco, 4, 2014, pp. 129-147. http://www.ehu.es/ojs/index.php/ars-bilduma/article/view/7110 (Consultado el 20/08/2018).

19 LÓPEZ BAHUT, E.: Jorge Oteiza y lo arquitectónico, op. cit., epílogo, p. 108

20 En esta idea insiste GARCÍA ÁLVAREZ, C.: Gaudí. Símbolos del éxtasis. Madrid, Siruela, 2017, s.p. Alude también a ello RACIONERO GRAU, L.: Antoni Gaudí: el so de la pedra. Barcelona, Edicions 62, 2009 
DEVA, escuela a la cual he retirado toda mi confianza"21. Y concluye que "el hotelero ve también $1^{\circ}$ el espacio", afirmación de la que participan tanto él como "Chi(llida)" (p. 98). Si Gaudí alude a la tradición familiar calderera, Oteiza hace lo propio con la hotelera tanto en su caso (sus padres regentaron un hotel en San Sebastián) como en el de Chillida (su abuela dirigió el Hotel Biarritz en la capital donostiarra).

\section{ALREDEDOR DE LA BAUHAUS: GROPIUS, MIES VAN DER ROHE Y} MAX BILL

Se agrupa bajo este enunciado un conjunto de textos relacionados con Walter Gropius y Mies van der Rohe, primer y último director de la Bauhaus respectivamente, así como con Max Bill, alumno de la escuela cuya obra giró en torno a la misma.

\subsection{Gropius y Mies van der Rohe: creación estética, necesidad espiritual y geometría}

El arquitecto alemán Walter Gropius, fundador en 1919 en Weimar de la escuela de diseño conocida como la Bauhaus, escribe Alcances de la arquitectura integral (La Isla, Buenos Aires, 1957, FB-1573, Sign. 1444). Oteiza se interesa por el artículo "Not Gothic but Modern for Our Colleges" (Moderno, que no gótico, para nuestras universidades), publicado en The New York Times el 23 de octubre de 1949, en el que Gropius instaba a romper con los estilos del pasado. En el mismo, a propósito del concepto dinámico de belleza como estímulo para el hombre, el escultor vasco matiza su conclusión de que la arquitectura debe apoyarse en los cambios sociales y técnicos de las dos últimas generaciones, al añadir que

21 "Escuela de Deva", s.l. s.f. AFMJO, FD-5210. Para profundizar en las causas que llevaron a Oteiza retirar su confianza a la Escuela de Deba, véase "Mi último disgusto y rompimiento definitivo con la Escuela de Deva”, Zarauz, 14 de agosto de 1972. AFMJO, FD-9774. Diversos autores reflexionan acerca de la implicación de Oteiza en el proyecto docente de Deba; citemos aquí, por tratar específicamente este tema, los estudios de MAKAZAGA, L. y VADILLO, M.: La Escuela Experimental de Arte de Deba: una apertura hacia la vanguardia. Deba, Debako Ostolaza Kultur Elkartea, 2005; VADILLO, M. y MAKAZAGA, L. Los proyectos educativos de Jorge Oteizo. El Instituto de Investigaciones Estéticis.

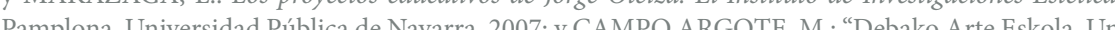
Pamplo experiencia singular". Ondare, 26, 2008, pp. 177-190. Este último apunta (p. 179), entre las causas de la corta vida del centro, el carácter utópico y maximalista de Oteiza, que chocaba con los planteamientos educativos y su transmisión. debe atender “¡a las necesidades espirituales!” (p. 94). No es esta la única ocasión en la que Oteiza polemiza con Gropius acerca de este asunto, por cuanto en su escrito "El espíritu del arte” (AFMJO, FD-10072) se muestra contrario al arquitecto alemán y afirma que el arte obedece a las leyes del espíritu. Contradice además su afirmación de que el hombre necesita impresiones cambiantes para mantener en estado de alerta sus capacidades receptivas, pues a su juicio es "al revés" (p. 93). En efecto, ante la ilusión del movimiento como estímulo que tratan de crear los artistas contemporáneos, Oteiza responde que se trata de "uno de los errores de partida del A(rte) C(ontemporáneo), error de Gropius y del Bauhaus, que es olvidar o desconocer que fuera de un arte mecanismo de expresión existe la realidad metafísica del $\mathrm{H}(\text { ombre })^{\prime 22}$.

Gropius es asimismo protagonista de Walter Gropius y el Bauhaus (Nueva Visión, Buenos Aires, 1957, FB-4594, Sign. 4056), libro del teórico del arte italiano Giulio Carlo Argan que Oteiza firma en Irún en febrero de 1959. A lo largo de sus páginas, el escultor sigue con interés la evolución de su pensamiento teórico primero en Europa y más tarde en Estados Unidos, alineándose con este último. Así, ante la afirmación de Argan de que el mito europeo de Gropius es la razón, considera que "confunde creación estética con forma útil", lo que le lleva al diseño industrial. Pero cuando en América cae el mito de la racionalidad y defiende la autenticidad de la existencia humana mediante la creación artística, exclama: “Ah! Ya no es lo de antes" (pp. 25-26). Vuelve a insistir en que si el arte no es más que la perfección de un hacer en la esfera social "es solo diseño industrial” (p. 29), calificando de error el pensamiento de Gropius de que todo cuanto circunda al hombre se inscribe en el ámbito de la actividad social (p. 131). El mismo juicio le merece la teoría de que una arquitectura en movimiento crea el espacio (p. 111), y tampoco está de acuerdo con que el pensamiento de una realidad cambiante se encuentre en la base de la enseñanza, sino que es "al revés" (p. 54). Sobre la posibilidad de separación de espacio y tiempo, o la reducción del tiempo al espacio por medio de la perspectiva, Oteiza lo califica de "falsedad" y "majadería", pues "lo que hace la perspectiva es poner T(iempo) en el E(spacio)"; y concluye que "hay un T(iempo) objetivo que hoy se acusa más. Este T(iempo) debiera haber investigado el Bauhaus" (pp. 134-135).

Por su parte, Ludwig Mies van der Rohe (Infinito, Buenos Aires, 1956, FB-1103, Sign. 436) es un libro recopilatorio de textos, conferencias y correspondencia del arquitecto alemán Mies van der Rohe, publicado por el también arquitecto y artista suizo Max Bill. La mayoría

22 “Gropius", s.l., s.f. AFMJO, FD-13976; y “Gropius", s.l., s.f. AFMJO, FD-18808 
de las anotaciones de Oteiza son subrayados que se acompañan de signos de interrogación que traducen su sorpresa o desacuerdo ante alguna de las posiciones teóricas del arquitecto. Así queda de manifiesto en aforismos tales como "La forma no es la finalidad de nuestro trabajo, no existe por sí misma" de Mies, ante el cual Oteiza le interpela: "Entonces, ¿por qué partes de (símbolos de cubo y esfera)?” (p. 29). El escultor no puede dejar de preguntar por las formas geométricas puras a un arquitecto al que la geometría de Mondrian, en su cuadriculación del espacio blanco inscrito entre las rectas que se cruzan ortogonalmente sobre el lienzo, le sirvió como modelo espacial de su arquitectura ${ }^{23}$.

\subsection{Max Bill: arte concreto, muralismo e influencias}

Hemos mencionado ya a Max Bill, acerca del cual la biblioteca personal de Oteiza cuenta con el libro Max Bill (Nueva Visión, Buenos Aires, 1955, FB-5758, Sign. 5486), escrito por el pintor y teórico argentino Tomás Maldonado y que firma el 29 de enero de 1957. Conviene recordar que el escultor vasco afirma tener "puntos de contacto con Max Bill", a quien califica en uno de sus escritos de "ecléctico" 24 y en cuya teoría del arte se apoyó para posicionarse en el panorama artístico internacional ${ }^{25}$, si bien trató de minimizar su influencia en beneficio de Kazimir Malévich, de quien se reconoce heredero: "Yo llego de Malévich directamente", leemos en su Propósito experimental ${ }^{26}$

23 Aspecto este último sobre el que reflexiona MADERUELO RASO, J.: La idea del espacio en la arquitec tura y el arte contemporáneos, 1960-1989. Madrid, Akal, 2008, p. 37.

24 "Creo que Max Bill es un ecléctico y lo eran todos estos grandes precursores que él trató. Para mí, verdaderamente original en Max Bill y que a mí me impresiona, fue una pequeña pintura que vi en Río Sao Paulo un Cuadrado dividido verticalmente en dos rectángulos de color que imperceptiblemente se Sao Pall, $\mathrm{Cud}$. iba convirtiendo en un círculo" "Aclaraciones sobre mi comportamiento como escultor" Irún, octubre de 1973. AFMJO, FD-6049.

25 Oteiza reconoce su afinidad (también sus diferencias) con Max Bill en diversos documentos, entre los que destacamos por su proximidad cronológica al texto que nos ocupa "Explicación de mi semejanza diferencias de mi teoría espacial con el grupo de Denis Renée, por un lado, y de Max Bill". Madrid, 4 de febrero de 1957. AFMJO, FD-3195.

26 Acerca de la relación entre Oteiza y Max Bill reflexionan FULLAONDO, J. D.: "Max Bill", Nueva Forma, 92, 1973, número monográfico dedicado a Max Bill; SAN MARTíN, F. J. y MORAZA, J. L. Oteiza. Laboratorio de papeles. Paper laborategia Alzuza, Fundación Museo Jorge Oteiza, 2006, pp. 124-126;

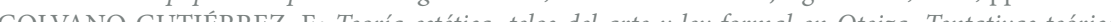

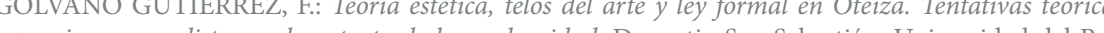
$y$ praxis vanguardista en el contexto de la modernidad. Donostia-San Sebastián, Universidad del Pais Vasco, 2017, pp. 209-212. Tesis doctoral dirigida por M. Iriondo Aranguren y A. Casado da Rocha. http://hdl.handle.net/10810/24486 (Consultado el 22/10/2018); y LÓPEZ BAHUT, E.: Jorge Oteiza y lo
Los numerosos comentarios se localizan tanto en el capítulo introductorio de Maldonado titulado "Max Bill" (pp. 7-13) como en los posteriores escritos del artista suizo: "La concepción matemática del arte en nuestro tiempo" (pp. 33-35), "Un monumento" (pp. 67-69) y "Forma, función, belleza” (pp. 118-119), así como en las láminas que los ilustran.

Oteiza establece un intenso diálogo con Max Bill a propósito del concepto de arte concreto, expresión empleada por primera vez en 1930 por Theo van Doesburg y desarrollada entre otros artistas por Bill en su diferenciación del arte abstracto. Acerca de los elementos que según este último caracterizan el arte concreto (producción de campos de energía y creación de ritmos con ayuda del color, no para documentar una realidad sino para crearla), Oteiza considera que "no es suficiente esta definición", por cuanto "también lo abstracto puede conseguirlo por fisión de un cuerpo" (p. 10).

Se identifica, y así lo da a entender mediante la expresión "= yo", con las nociones de continuo-discontinuo, preciso-impreciso y limitado-ilimitado que tienen origen científico y caracterizan el repertorio temático de Max Bill (p. 12). Y está de acuerdo con el suizo en que la pintura de caballete sobrevivirá a la mural, si bien no deja de interrogarse acerca de la convicción de aquel de que la era de la pintura mural ha terminado (p. 12). No sorprenden las reticencias acerca del final del muralismo en quien en 1935 viajó a Hispanoamérica con el objetivo de elaborar una nueva propuesta estética basada en la escultura precolombina y el muralismo mexicano, el cual está muy presente en su Carta a los artistas de América (Popayán, Colombia, 1944) ${ }^{27}$. Si a todo ello sumamos su interés por uno de sus grandes exponentes como es David Siqueiros, puesto de manifiesto en los numerosos comentarios a su libro Cómo se pinta un mural (México, Ediciones Mexicanas, 1951, FB-4591, Sign. 4266)

arquitectónico, op. cit.,pp. 79-81, quien, a propósito de los numerosos comentarios del escultor al libro de Maldonado, concluye que "el interés de Oteiza por Max Bill enmarca una nueva línea de investigación que podría ser desarrollada con más profundidad posteriormente, pues se establecen paralelismo interesantes"

27 OTEIZA, J.: "Sobre el arte nuevo en la post-guerra: carta a los artistas de América", Revista de la Universidad del Cauca, 5, 1944, pp. 75-109. En este texto, Oteiza aborda el muralismo mexicano desde los conceptos de espacio y tiempo plásticos para concluir que no supone una verdadera renovación del arte contempoŕneo planteando a continuacín su concepto de muro como elemento sobre el que consconter uno

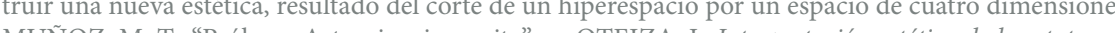
MUNOZ, M. I., "Prologo. Arte, ciencia y mito, en OTEIZA, ... Interpretación estetica de la estatuaria megalítica americana. Carta a los artistas de América sobre el arte nuevo en la posguerra (coords. M. MUNOZ, J. LIZASOAIN, y A. RUBIO). Alzuza, Fundación Museo Jorge Oteiza, 2007, pp. 65-67. 
y en sus bocetos iniciales para la fachada de Aranzazu, que parece trabajar como si de un gran mural escultórico se tratara con el recuerdo de Diego Rivera como telón de fondo ${ }^{28}$ entenderemos el posicionamiento de Oteiza al respecto.

El artista oriotarra considera que buena parte de la teoría de Max Bill procede de otros artistas. Así, en Vassily Kandinsky encuentra el origen de las relaciones entre forma y función ("viene de Kandinsky", p. 9) y de la unidad artística en términos de fusión en el espacio que propugna el suizo (p. 12). Pero por encima de otros nombres emerge el de Malévich, en quien a su juicio se sustenta todo el entramado teórico de Bill. De hecho, cuando este considera la geometría como el elemento primario de toda obra plástica, Oteiza le recuerda que "esto hizo Malévich" (p. 34); y acerca de la recreación del mundo real en la obra artística, Max Bill cita a Klee, Brancusi, Kandinsky y Mondrian, pero el vasco le recrimina: “¿y Malévich? ¿Por qué no hablas de él?” (p. 33). A partir de este reproche, insiste una y otra vez en la importancia del pintor ruso a la hora de determinar la dimensión matemática del arte actual, del que forman parte artistas que se expresan "a lo Malévich. ¿como tú y yo?” (p. 34), interpela al suizo, en lo que parece un reconocimiento tácito de su deuda con el creador del suprematismo, con el que comparte conceptos como el de las "unidades Malévich". Es más, no concibe las posibilidades de una evolución del arte de las últimas décadas sin "mi replanteamiento de Malévich. Yo quiero decir esto que Malévich no dijo y que hoy hubiera intentando pensar" (pp. 34-35), arrogándose así el papel de intérprete válido de las ideas del ruso.

La conclusión a la que parece llegar es que gran parte de la teoría matemática de Max Bill encuentra su fundamento en el suprematista; así se desprende de su sentencia final: "Si hubieras citado a Malévich, hubieras tenido muy poco que decir" (p. 35). Y por ello no duda en afearle su conducta a propósito de su obra Cuadrado blanco (1946): "Sigues olvidándote de Malévich y escarbando en sus bolsillos” (p. 57), en alusión sin duda a Blanco sobre blanco (1918).

28 Explícito de ello se muestra una fotografía de Oteiza en su estudio de Madrid, fechada hacia 1952, apenas cuatro años después de su regreso de América; en la pared del fondo aparecen tres imágenes que identificamos con otros tantos detalles del mural La conquista y revolucion realizado por Rivera en torno a 1930 para el Palacio de Cortés en Cuernavaca. El motivo no carece de interés si tenemos presente que en estos momentos se encuentra imbuido de lleno en su proyecto de Aranzazu, tal y como comprobamos en otros objetos del estudio como las esculturas y un boceto de la fachada que parec cra Vejur como de un ón

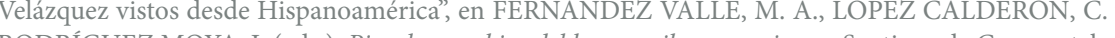
RODRÍGUEZ MOYA, I. (eds.): Pinceles y gubias del barroco iberoamericano. Santiago de Compostela y Sevilla, Andavira, 2019, p. 408.
Más allá de Malévich, Oteiza halla igualmente puntos de contacto en las obras de Max Bil con Mondrian, van Doesburg y Kandinsky, en el caso de este último no solo a nivel forma sino también terminológico, como comprueba en la obra del artista suizo Cinco acentos en diferentes direcciones (1944), donde rodea la palabra "acentos" y significa: "vocabulario Kandinsky" (p. 52), quien ya la había empleado como título (Acento en rosa, 1926); y lo mismo ocurre con la expresión "céntrica-excéntrica" que figura en otra de sus obras (p. 47) y que podemos leer en Punto y línea sobre el plano (1926). Un nuevo comentario le suscita Acentos desde el amarillo (1946), cuyo carácter retardatario impide una evolución que el escultor vasco sí ha sido capaz de llevar a cabo: "Seguís con la psicología del color desde el Bauhaus y Kandinsky. Yo estoy con los colores espaciales. Los no-colores de Kandinsky" (p. 60). Oteiza ya se había interesado páginas atrás por la ausencia de estilo que propugna la Bauhaus a partir de los postulados de van Doesburg y Gropius, sustituyendo el concepto de "estilo aestilístico" que propone Maldonado por el de "estilo impersonal" (p. 8).

Tampoco faltan conexiones entre Max Bill y su propio pensamiento y obra, como en Construcción céntrica-excéntrica (1941), en la que descubre "mi respiración formal. Condensación-dilatación", en referencia a su interpretación de la historia del arte como "un ritmo respiratorio" por las dilataciones y contracciones del espacio arquitectónico en sus diferentes edades ${ }^{29}$. Por su parte, la Construcción con ocho acentos similares (1944) le evoca su Unidad triple liviana (p. 50), en relación con el "espacio liviano, dinámico, en expansión" sobre el que ya reflexionaba en páginas anteriores y al que volverá a aludir en Construcción con negro, lila, anaranjado y blanco (1944-45) que acompaña de la expresión: "unidades livianas" (p. 54). Y el proyecto del Monumento al prisionero político desconocido con el que Max Bill concurrió al concurso internacional de Londres de 1952 lleva a Oteiza a realizar un esquemático dibujo de su Prometeo, que personaliza con la expresión “yo” (p. 56)

Otra obra con la que establece conexiones es Superficie rectangular en el espacio con limitaciones de igual longitud (1952), que relaciona con su "lámina rectangular desarrollando un E(spacio)" (p. 97), alusiva a su trabajo experimental con una chapa de metal plana que alabea otorgándole una realidad espacial tridimensional. El resultado son obras como Suspensión vacía (estela funeraria en homenaje al constructor aeronáutico René Couzinet) (1957), incluida en el catálogo que acompañó a las obras enviadas aquel año a la Bienal de

29 Tal concepción oteiciana de la historia del arte queda recogida en una de sus anotaciones al libro de ZEVI, B.: Saber ver la arquitectura. Buenos Aires, Poseidón, 1951, p. 54 (FB-4693, Sign. 4358). 
Sao Paulo ${ }^{30}$. Por último, la Superficie hexagonal en el espacio con circunferencia total (1953) lleva a Oteiza a realizar un esquemático dibujo que parece corresponder al Monumento al Padre Donosti en Agiña (Lesaka, Navarra, 1958) (p. 98)

En fin, en la "conversación" que mantienen escultor vasco y artista suizo no faltan las correcciones del primero al segundo. Acerca de los fundamentos de la doctrina de la forma de Max Bill, califica de error su idea de que la belleza vaya a la par de la función y sea en sí misma una función, pues Oteiza la entiende como "un resultado de la ecuación operadora o diseño (no existe antes)" (p. 9). Cuestiona el concepto de espacio que propone el suizo en su Construcción (1938), afirmando que "No son verdad espacial. Tienen que ser matrices intrínsecas y originales del E(spacio) en mí” (p. 84). Y completa la sentencia de Max Bill de que la forma es cuanto podemos ver en el espacio con "si está espacialmente justificado" (pp. 118-119). En cuanto a las preguntas de Bill sobre si el contenido permanece invariable y hasta qué punto los elementos expresivos tienen validez absoluta, Oteiza parece encontrar la respuesta en su conferencia Informe sobre el Encontrismo impartida en 1935 en la Academia de Bellas Artes de Santiago de Chile ${ }^{31}$, en la que aludía al "ocho" de Hans Arp, el "bastón" de Picasso, el "huevo" de Brancusi y el poliedro de Lipchitz, cuyos símbolos recoge en una anotación al margen (p. 34).

La documentación anexa que contiene el libro incluye una postal escrita por el arquitecto navarro Fernando Redón a Oteiza a su dirección madrileña de Ríos Rosas con motivo de su visita a Ronchamp, que confirma el interés del escultor vasco por la capilla corbusiana ("Me acordé de ti por lo que te hubiese gustado"32, refiere Redón), a la que Oteiza relacionaba con la propuesta plástica de Malévich ${ }^{33}$

30 BADIOLA, TX.: op. cit., pp. 668-673

31 Lipchitz, Brancusi, Picasso y Arp", s.l, s.f. AFMJO, FD-22338

32 "Postal de Fernando Redón a J. Oteiza", s.l., s.f. AFMJO, FD-9063. Pese a no poder descifrar las referencias del matasellos, debemos fechar la postal en torno a 1957, coincidiendo con el período en el que Oteiza residió en la calle Ríos Rosas de Madrid (antes de instalarse en Irún a comienzos de 1958), y quizás también con el viaje de estudios de Redón a la conclusión de la carrera, en el que visitó diversos ed ficios centroeuropeos, entre ellos el convento de La Tourette de Le Corbusier, cerca de Lyon. FERNÁN DEZ SALIDO, L. M.: Fernando Redón Huici, arquitecto. Pamplona, Gobierno de Navarra, 2006, p. 149

33 De hecho, Oteiza corrige a Giulio Carlo Argan cuando este asocia la definición plástica de Le Corbusier en Ronchamp con Picasso, pues a su juicio es "con Malévich". ARGAN, G.C.: El concepto del espacio arquitectónico desde el Barroco a nuestros díns. Buenos Aires, Nueva Visión, 1973 p. 174 (FB-5157,

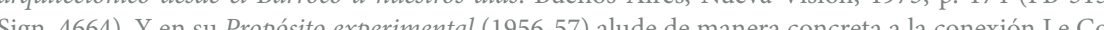
Sign. 4664). Y en su Proposito experimental (1956-57) alude de manera concreta a la conexion Le Corbusier 1988, p. 225. Abunda en esta idea LÓPEZ-BAHUT, E.: "De los collages y maquetas de vidrio de Oteiza al hormigón de Sáenz de Oíza”, VLC arquitectura. Research Journal, 3.1, 2016, pp. 55-83.

\subsection{La Bauhaus: profesorado y método de enseñanza}

Concluimos este apartado con La Bauhaus (Alberto Corazón Editor, Madrid, 1971; Reg 5471; Sign. 4168-2), obra colectiva que Oteiza firma -con ciertas dudas en cuanto al día- el 13 de enero de 1975. Los subrayados y comentarios constituyen un excepcional testimonio del afán pedagógico de Oteiza en la comprensión artística, relacionando los proyectos educativos emprendidos alrededor de la Bauhaus con su reciente experiencia personal en la Escuela Experimental de Arte de Deba, centro que siguió muy de cerca en algunos principios de su método de aprendizaje los de la escuela alemana.

Uno de los capítulos de este libro que capta su interés es "El Vchutemas: originalidad y conexiones de una experiencia didáctica en la U.R.S.S” (pp. 75-86), en el que el crítico y ensayista polaco Szymon Bojko aborda el método de enseñanza implantado en los talleres de enseñanza superior del arte y de la técnica creados en 1920 por el gobierno soviético, que gravitaba alrededor de los presupuestos del suprematismo y el constructivismo. No es de extrañar que Oteiza relacione la escuela con el "pintor Rodchenko" (p. 75), por cuanto fue Alexander Rodchenko quien desde la dirección de la sección de estética industrial se convirtió en su cerebro. Los principios generales sobre los que el constructivista ruso cimentó la doctrina del Vchutemas (revisión crítica de la teoría del arte aplicado, elaboración de la forma del objeto a partir de diversos condicionamientos, posición no conformista frente al mundo de los objetos) suscitan en Oteiza un comentario en términos de comparación: "muy superior todo lo de Deba" (p. 81), manifestando así la primacía de su proyecto.

Un análisis más profundo le merece "Los avatares de la Bauhaus. Gropius y sus artistas" (pp. 87-100), firmado por el crítico de arte italiano Mario de Micheli, que desarrolla la dimensión didáctica y pedagógica de la Bauhaus a través de los artistas llamados por Gropius para enseñar en la escuela. Uno de ellos fue el pintor suizo Johannes Itten, cuyo método de enseñanza, basado en la espontaneidad como recurso para comprender las formas de la naturaleza y en la captación de las propiedades de los materiales para entender su estructura es identificado por Oteiza con el "control y dominio sobre el E(spacio) y T(iempo) concretos". Y lo equipara igualmente con su "gimnasia vasca" (p. 93), actividad presente en sus proyectos de universidad vasca e ikastolas de los años sesenta. A Oteiza le interesaba la gimnasia como continuación de la danza y los deportes, de manera que desde la gimnasia sueca trató de redactar una gimnasia vasca aprendiendo a respirar, correr y saltar ${ }^{34}$.

34 SARASOLA RUBIO, F.: "Oteiza, escultor y arquitecto. Análisis de unos croquis inéditos para la Uni- 
La actividad teatral del artista alemán Oskar Schlemmer, que llevó a la escenografía el conjunto de las experiencias realizadas en la Bauhaus en todos los campos, vuelve a recordarle " $\mathrm{mi}$ gimnasia vasca" (p. 98). Los presupuestos teatrales de Schlemmer, que parten de lo elemental (colores simples, materias, espacio en sus leyes y misterio, posición del cuerpo), se encontraban, según de Micheli, muy lejos del teatro revolucionario que propugnaba el dramaturgo alemán Edwin Piscator; sin embargo, Oteiza matiza al crítico italiano, por cuanto a su entender tal planteamiento "era la base estética para la libertad total de los montajes" (p. 98).

Su recorrido por la Bauhaus le conduce hasta el arquitecto y urbanista suizo Hannes Meyer, cuyo audaz posicionamiento al frente de la escuela que dirigió entre 1928 y 1930 le llevó a posiciones de ruptura evitadas por Gropius. Oteiza se pregunta al respecto: “iparecido a mí?" (p. 99), identificación personal que vuelve a repetir en el capítulo titulado "Otra vez la Bauhaus. Textos, cartas, respuestas, comentarios” (pp. 175-190), recopilación de materiales de Tomás Maldonado. Considera el teórico argentino que dos textos de Meyer (Construir, 1928; Mi expulsión de la Bauhaus, 1930) contribuyeron a crear su imagen agresiva, lo cual suscita nuevamente la pregunta del escultor: “= yo?” (p. 179). Y más adelante, a propósito de los conflictivos resultados que según Maldonado (en carta a Gropius firmada en Ulm el 1 de noviembre de 1963) ha originado el dogmático funcionalismo del suizo, se ratifica en su idea: "= yo" (p. 186). Tan solo toma distancia en la consideración de Maldonado de que la actitud de Meyer se justifica por llegar demasiado tarde a todos los sitios (Bauhaus, Unión Soviética, México, Suiza), ya que Oteiza considera que “yo demasiado pronto" (pp. 186-187)

Otros asuntos de la recopilación de Maldonado captan su atención. Acerca de las raíces pedagógicas de la Bauhaus, afirma el argentino que el estudiante tiene que adquirir un conocimiento tanto intelectual como emocional, junto a lo cual Oteiza anota: "Mi epílogo Dr. Ubalde" (p. 177). Se refiere a "Un modelo de hombre para el niño en cada país", que escribió en 1972 para el libro La psicología entre la física y la ecología del psiquiatra Jesús Ubalde Merino, en el que trata de la educación artística y estética de los niños a través del juego, así como de la educación del niño como paso necesario para el cambio de la sociedad $^{35}$. A su vez, Maldonado considera las adversidades a las que estuvo expuesta la Bauhaus en el contexto político, social y económico de su época, ligada desde el principio

versidad Infantil Piloto e Ikastola Experimental en Elorrio. 1964", Expresión Gráfica Arquitectónica 26, 2015, pp. 100-109. El propio Oteiza abunda en estas ideas en su escrito "Gimnasia vasca", s.l., s.f. AFMIO FD-8936

35 "Epílogo para el Dr. Ubalde", s.l., s.f. AFMJO, FD-9868; “Un modelo de hombre para el niño en cad al destino de la democracia alemana, realidad que suscita en Oteiza el siguiente paralelismo en relación con el escenario vasco del momento: "= Deva: con la represión cultural y la indiferencia y alejamiento de los industriales vascos” (p. 181).

Las últimas consideraciones de Oteiza en el libro manifiestan su disconformidad con la postura de Gropius ante la enseñanza del arte. Primero de manera comedida, cuando en una carta del alemán a Maldonado firmada en Cambridge el 24 de noviembre de 1963 Oteiza subraya y coloca entre interrogantes la afirmación de Gropius de que "el arte no debe aprenderse" (p. 188). Y luego con mayor vehemencia cuando acerca de los principios de la Bauhaus, Gropius asevera que "el arte en sí mismo no puede enseñarse, pero los oficios sí", ante lo cual el escultor no puede contenerse y tras subrayar la primera frase y acompañarla de un interrogante, exclama: “iClaro que sí!” (p. 193).

\section{EL FUNCIONALISMO: LE CORBUSIER Y EL MODULOR}

La arquitectura funcional tiene en el arquitecto suizo nacionalizado francés Charles Édouard Jeanneret, más conocido como Le Corbusier, a uno de sus principales representantes, por quien Oteiza muestra interés desde su etapa en Sudamérica. Incluso estableció con él contacto personal, por cuanto Le Corbusier le escribe una carta firmada en París el 23 de septiembre de 1957 agradeciéndole el envío de su catálogo Propósito Experimental 19561957, a la vez que pide le remita un segundo ejemplar para su amigo el escultor bretón Joseph Savina ${ }^{36}$.

Son varios sus textos conservados en la biblioteca oteiciana, entre los que se encuentra $E l$ Modulor (Poseidón, Buenos Aires, 1953, FB-4683, Sign. 4357). El índice personal de Oteiza pone de manifiesto su atracción por los temas concernientes a la ocupación del espacio por el hombre, las proporciones en la naturaleza y en el arte a partir de la sección áurea, el número de oro y la serie de Fibonacci, y el sistema arquitectónico basado en la escala humana (el Modulor).

pás" Irún, julio de 1972. AFMJO, FD-17960; UBALDE MERINO, J.: La psicología entre la física y ecología: la dialéctica de la energía como base de las ciencias. Santander, Jesús Ubalde Merino, 1973. MARTÍNEZ GORRIARÁN, C., op. cit., pp. 326-328

36 "Carta de Le Corbusier a J. Oteiza", París, 23 de septiembre de 1957. AFMJO, FD-786 
Acerca de la ocupación espacial, ante la afirmación de Le Corbusier de que "la primera prueba de existencia es ocupar espacio", recuerda que "así comenzaba yo la Estética racional (Anatomía del Espacio) ${ }^{37 ’}$ (p. 26). Y desarrolla sus conceptos de ocupación objetiva (expresión) y desocupación subjetiva (receptividad) en la arquitectura (p. 69). Subraya con el arquitecto suizo un factor clave del espacio interno: la escala, es decir, la relación entre las dimensiones del edificio y del hombre "y su velocidad", o lo que es lo mismo, "su vida funcional". A su entender, el funcionalismo corbusiano representa "lo abstracto", "lo binario" y la "4a di(mensión)" que introduce el tiempo, en tanto que el organicismo de Frank Lloyd Wright expresa "lo ternario u orgánico o funcionalismo absoluto", la "5a di(mensión)" que integra el ámbito vital de la persona.

En cuanto al sistema de proporciones, la figura clave es el filósofo e historiador rumano Matila Ghyka, cuya mayor preocupación residió siempre en la síntesis entre matemática y poesía ${ }^{38}$. Reconoce Oteiza con Le Corbusier que cuando tuvo conocimiento de su teoría (poco después de su llegada a Hispanoamérica en 1935) no estaba preparado para su comprensión matemática, pero sí mediante las figuras que la interpretaban ${ }^{39}$ (p. 25); y realiza multitud de cálculos a partir de las propuestas numéricas del libro que en muchas ocasiones se traducen en gráficos y diagramas (pp. 33 y 59). La relación y proporción numéricas, la armonía matemática y el concepto geométrico-artístico de la sección áurea fueron temas de constante estudio y aplicación práctica en el escultor vasco, buena prueba de su obsesión por la formulación matemática universal ${ }^{40}$.

37 "Una anatomía del espacio como introducción a la nueva estética", s.l, s.f. AFMJO, FD-7862

8 Matila Ghyka destacó por su exhaustivo estudio de la sección áurea a la que dedicó numerosos textos. DÍAZ EREÑO, G.: "Mi piedra de catalejo", en Exposición Oteiza 1935-1975. La casa del Ser. Valladolid, Caja de Burgos, 2010, s.p.; MARTÍNEZ GORRIARÁN, C.: op. cit., pp. 68, 90 y 97.

39 Se conservan en la biblioteca personal de Oteiza tres libros de Ghyka: Le nombre dor (I) (Librairie Gallimard, Paris, 1931); Estética de las proporciones en la naturaleza y en las artes (Poseidón, Buenos Aires, 1953); y El número de oro (II) (Poseidón, Buenos Aires, 1968). Los dos primeros -y en menor medid el tercero- contienen diversos subrayados y anotaciones, con alusiones a la sección de oro, a la serie de Fibonacci, al número Phi y a la espiral logarítmica, entre otros temas.

40 Esclarecedor resulta en este sentido el trabajo de SÁNCHEZ SIMÓN, I: Oteiza y los nuevos paradigmas científicos. Alzuza, Fundación Museo Oteiza, 2012. Véase también AZANZA LÓPEZ, J. J.: Crónica de un fracaso: Jorge Oteiza, Felipe IV y el VIII Centenario de San Sebastián (1950). Cuadernos del Museo Oteiza, 8. Alzuza, Fundación Museo Jorge Oteiza, 2013; y AZANZA LÓPEZ, J. J.: "Arte y estética en lo Minutogramas de Jorge Oteiza”, Archivo Español de Arte, 361, 2018, pp. 48-51.
Sobre la escala humana como guía para la arquitectura, se alinea con gran parte de las propuestas de Le Corbusier. Cuando este afirma que "la arquitectura actúa sobre standars", recuerda su conferencia Informe sobre el Encontrismo impartida en 1935 en Santiago de Chile, en la que mencionaba el concepto de "unidades standar" a propósito del problema de elegir racionalmente un número de formas elementales geométricas capaces de combinarse en construcciones más complejas ${ }^{41}$ (p. 29). Y observa cómo actúan sobre el Modulor las dos series matemáticas (roja y azul) que propone Le Corbusier, para comprobar que el "viejo Modulor" basado en la estatura de un hombre francés de 1,75 m. plantea "dificultad con pulgadas", problema que se soluciona con un nuevo Modulor sobre la base de un policía británico de seis pies (1,8288 m). (pp. 45-46, 50, 59-60, 66, 121 y 135) (Fig. 4). Es tal su interés que incluso tenía pintadas las proporciones del Modulor en uno de los pilares de su vivienda-taller de Irún ${ }^{42}$.

Oteiza relaciona además este doble cálculo con el fenómeno sonoro conocido como efecto Doppler, que entiende como "mi ley de crecimiento y decrecimiento de la expresión" en el plano estético (p. 46) y al que hace referencia en su Quousque Tandem.... ${ }^{43} \mathrm{Y}$ a propósito de las medidas de la sección áurea en la denominada serie roja, significa: "Aquí esta la contestación de Stockhausen a Vallet" (p. 59). Se refiere al compositor alemán y uno de los mayores representantes de la música electrónica del siglo XX Karlheinz Stockhausen, que en piezas como Klavierstück IX (1954) hizo de la sección áurea el eje estructural de la misma; y al arquitecto guipuzcoano Luis Vallet de Montano, con quien Oteiza colaboró en diversos proyectos como la vivienda-taller de Irún y el conjunto monumental en memoria del Padre Donosti en la estación prehistórica de Agiña, en Lesaka, ambos de $1958^{44}$.

41 "Lipchitz, Brancusi, Picasso y Arp", s.l., s.f. AFMJO, FD-22338.

42 "De pronto me fijé en el sótano de Irún donde trabajaba, que, en mi admiración e interés por Le Corbusier, tenía en una columna verticalmente pintados sus 2 modulores, el rojo y el azul si no recuerdo mal..." La cita corresponde a El final del arte contemporáneo, texto redactado por Oteiza para el catálogo de la exposición Jorge Oteiza-Néstor Basterrechea celebrada en 1960 la Galería Neblí de Madrid, reproducido en Oteiza. Propósito experimental. Barcelona, Fundación Caja de Pensiones, 1988, p. 230 Cit. por LÓPEZ BAHUT, E.: Jorge Oteiza y lo arquitectónico, op. cit., pp. 174 y 190.

43 Oteiza alude en varios escritos personales de los años sesenta y setenta al efecto Doppler, en el que entran en juego la intensidad del sonido y la distancia al foco sonoro.

44 Sobre este conjunto monumental, véase ARNAIZ, A.: "Entre escultura y monumento. La estela de tes Plásticas y Monu . Piedra en el paisaje. Cuadernos del Museo Oteiza 2 Alzuza, Fundación Museo Jorge Oteiza, 2006; y ETXEPARE IGIÑIZ, L. y GARCÍA NIETO, F.: Luis Vallet de Montano (1894-1982). Arquitecto de frontera. San Sebastián, COAVN Delegación de Gipuzkoa 2015, pp. 195-216. 
Dejemos un momento nuestros cálculos por una digresión económica y sociológica:

Los Estados Unidos autorizan perfectamente a Kayser genial hombre de negocios y audaz industrial, a producir

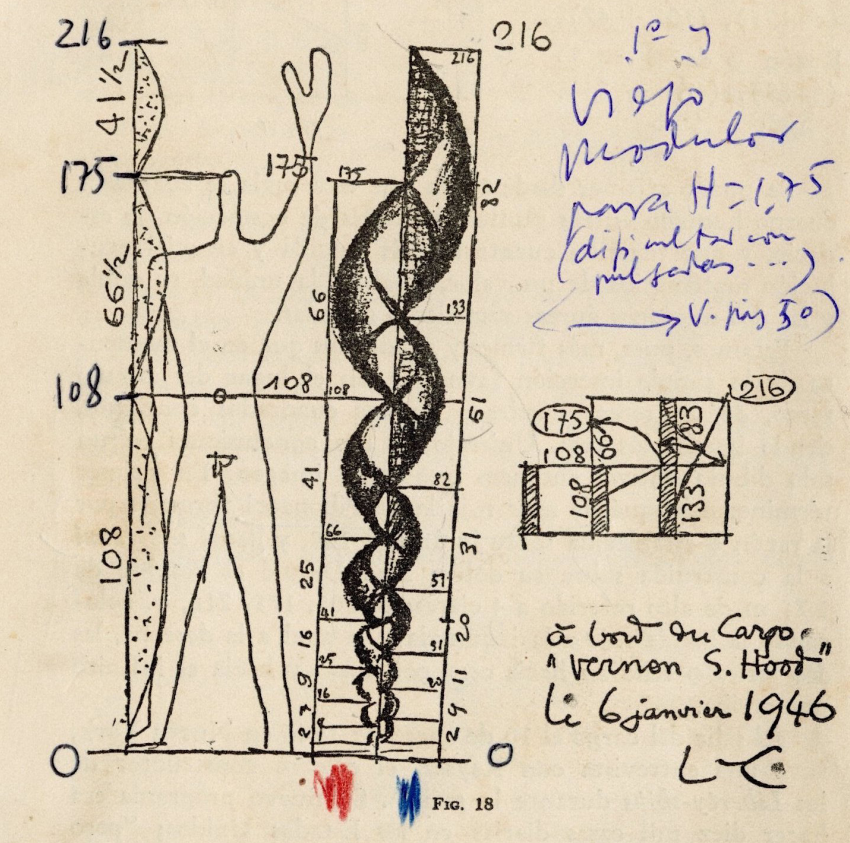

anualmente tres millones de casas en serie, $y$, por tanto, $\mathrm{fa}$ miliares, que ocuparán espacio y formarán calles; pero éstas no estarán en una ciudad, donde no hay sitio, sino en el campo. Las ciudades se extenderán desmesuradamente: subur-

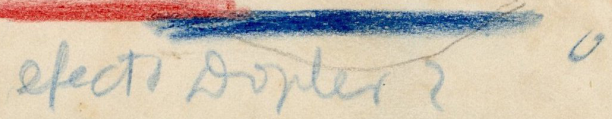

Fig. 4: Le Corbusier, El Modulor. Anotación personal de Jorge Oteiza. AFMJO, FB-4683 Sign. $4357 \odot$ Jorge Oteiza $\odot$ Pilar Oteiza, A+V Agencia de Creadores Visuales, 2020
Conviene destacar a este respecto que el escultor conocía personalmente a Stockhausen, quien viajó a Pamplona en noviembre de 1961 con motivo de una serie de conciertos coordinados por el compositor tudelano Fernando Remacha ${ }^{45}$; de hecho, Oteiza, Remacha y Stockhausen cenaron una noche en el restaurante Aralar de Pamplona, y después se reunieron para escuchar música del alemán ${ }^{46}$. Oteiza asiste a sus conferencias, analiza su pieza El canto de los adolescentes (1956) y compara su música con la "ley de los cambios", herramienta conceptual de creación propia para sistematizar la evolución cíclica de los lenguajes artísticos. Es en este contexto en el que debe inscribirse la referencia oteiciana, pues en el intercambio epistolar con Remacha de este período se suceden las alusiones a Vallet, interesado igualmente en la música electrónica.

Prefiere la palabra "parrilla" a la de "enrejado" para el término francés grille que se encuentra en la génesis del Modulor (p. 32). Le interesan las conversaciones de Le Corbusier con Einstein y con Mougeot, fundador en París del Comité de Organización Económica; y acerca de la reflexión de este último de que el Modulor debe aplicarse por igual a la mecánica y a la arquitectura, señala: "Yo agregaré: y deberá ensayarse su aplicación a la ley de los cambios del lenguaje artístico. En función de la escala humana, los recorridos del genio humano, sus variaciones, están también a escala humana” (pp. 52-53).

Oteiza incorpora al libro un conjunto de documentos que complementan sus anotaciones, con comentarios relativos al Modulor y a las dos series matemáticas que actúan sobre este, a la elección de unidades stándar, a la sección áurea y a la ocupación del espacio por la estatua ${ }^{47}$. Son también interesantes los dibujos que acompañan a las notas, que en algunos casos reproducen las ilustraciones del libro (Fig. 5), mientras que en otros parecen ser bocetos de esculturas de composición tubular acompañadas de expresiones como "fábrica de tubos" o "alambres" en las que se pregunta por el tema ("Bebedor?", "Orfeo") (Fig. 6). Debemos relacionar estas últimas con un conjunto de piezas del Laboratorio experimental

45 "Reunión con Stockhausen", Pamplona, 25 de noviembre de 1961. AFMJO, FD-9941. Nuevamente volverá a interesarse por el compositor alemán con motivo de un artículo publicado en febrero de 1964 en la Revista de Occidente sobre Stockhausen y la música electrónica. "Música electrónica e instrumental. Stockhausen", s.l., s.f. AFMJO, FD-19743.

46 ANDRÉS VIERGE M. Fernando Remacho. El compositor y su obra Madrid, Instituto Complutense de Ciencias Musicales, 1998, pp. 231-232; id.: "Cuatro cartas de Fernando Remacha (1898-1984) a Jorge Oteiza (1908-2003)", Revista Príncipe de Viana, 249, 2010, p. 76.

47 "Modulor para estatuas interiores", s.l., s.f. AFMJO, FD-18655; "Dibujos de obra", s.l., s.f. AFMJO, FD18656 


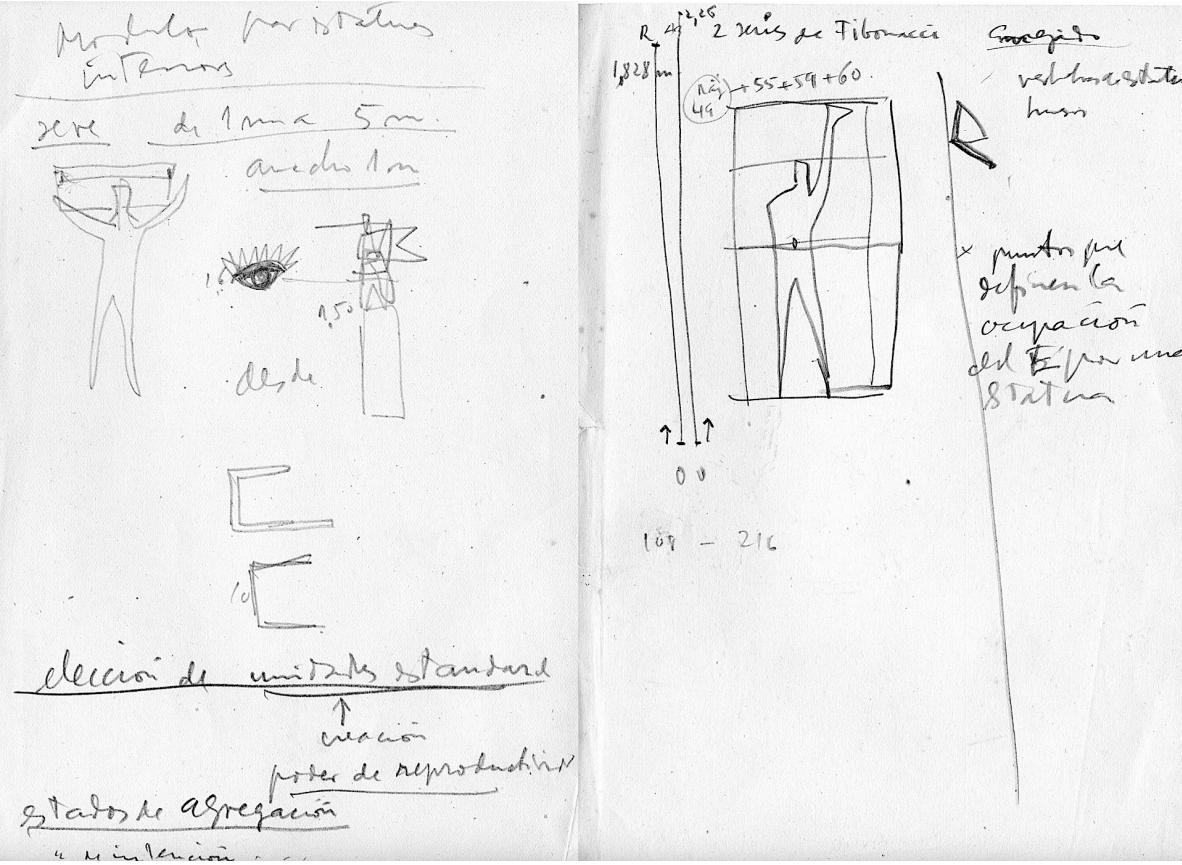

Fig. 5: Jorge Oteiza, "Modulor para estatuas interiores", s.l., s.f. Documento intercalado en las páginas de El Modulor AFMJO, FB-4683, Sign. 4357 @ Jorge Oteiza @ Pilar Oteiza, A+V Agencia de Creadores Visuales, 2020

de los años cincuenta caracterizadas por una lógica espacial vinculada al movimiento en las que aborda el estudio de los sólidos en suspensión, en la línea de realizaciones como su boceto para el Homenaje a Luis Martín Santos (1956) y Piedra para jardín contra muro ciego $(1956-57)^{48}$

Le Corbusier es igualmente el autor de Cuando las catedrales eran blancas (Poseidón, Buenos Aires, 1948, FB-4652, Sign. 4362), epopeya de la arquitectura medieval enfrentada a las modernas catedrales del urbanismo estadounidense que son los rascacielos. En sus

48 BADIOLA, TX.: op. cit., pp. 448-449 y 688-694

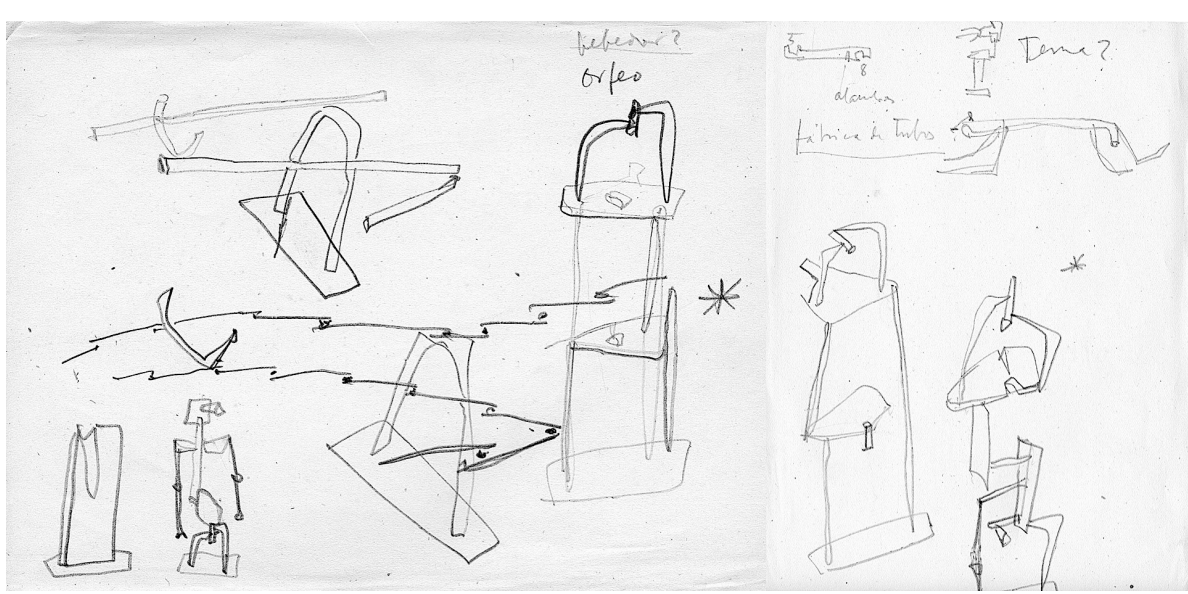

Fig. 6: Jorge Oteiza, "Modulor para estatuas interiores", s.l., s.f. Documento intercalado en las páginas de El Modulor AFMJO, FB-4683, Sign. 4357 @ Jorge Oteiza @ Pilar Oteiza, A+V Agencia de Creadores Visuales, 2020

páginas, Oteiza se interesa por el ingeniero musical Gustave Lyon y su diseño de la Sala Pleyel de París inaugurada en 1927, y por el promotor industrial Henry Frugès con su encargo de un grupo de casas a Le Corbusier en Pessac, suburbio de Burdeos.

No pasa por alto algunas reflexiones corbusianas, como el equivocado método de enseñanza de l'Ecole des Beaux-Arts de París, en el que el dibujo aniquila a la arquitectura, ante lo cual Oteiza exclama: “Estoy harto de decirlo!” (pp. 166-167). Y no deja de lado las respuestas al cuestionario que en 1935 planteó a Le Corbusier el arquitecto americano Percival Goodman a propósito de cuestiones como la estandarización de la producción arquitectónica y el sistema de educación arquitectónica, a cuyo juicio debe partir de la base de la imaginación, la poesía y el sentido plástico, a lo que añade: "Yo en Bogotá: Anatomía del E(spacio) para arquitectura 10" (p. 276). Recuerda a este respecto el escultor colombiano Edgar Negret, amigo de Oteiza, el lamento del vasco porque en América solo se enseñaba anatomía del cuerpo humano y no del espacio. Por último, la liberación de la axila de la bóveda que dio lugar al arco ojival y al nacimiento de las catedrales, cede ante el hiperboloide en el que "la masa (está) en el exterior", tal y como refleja Oteiza en sendos esquemáticos dibujos que muestran la diferencia entre masa y vacío en la catedral gótica y en el hiperboloide contemporáneo (p. 284) (Fig. 7). 


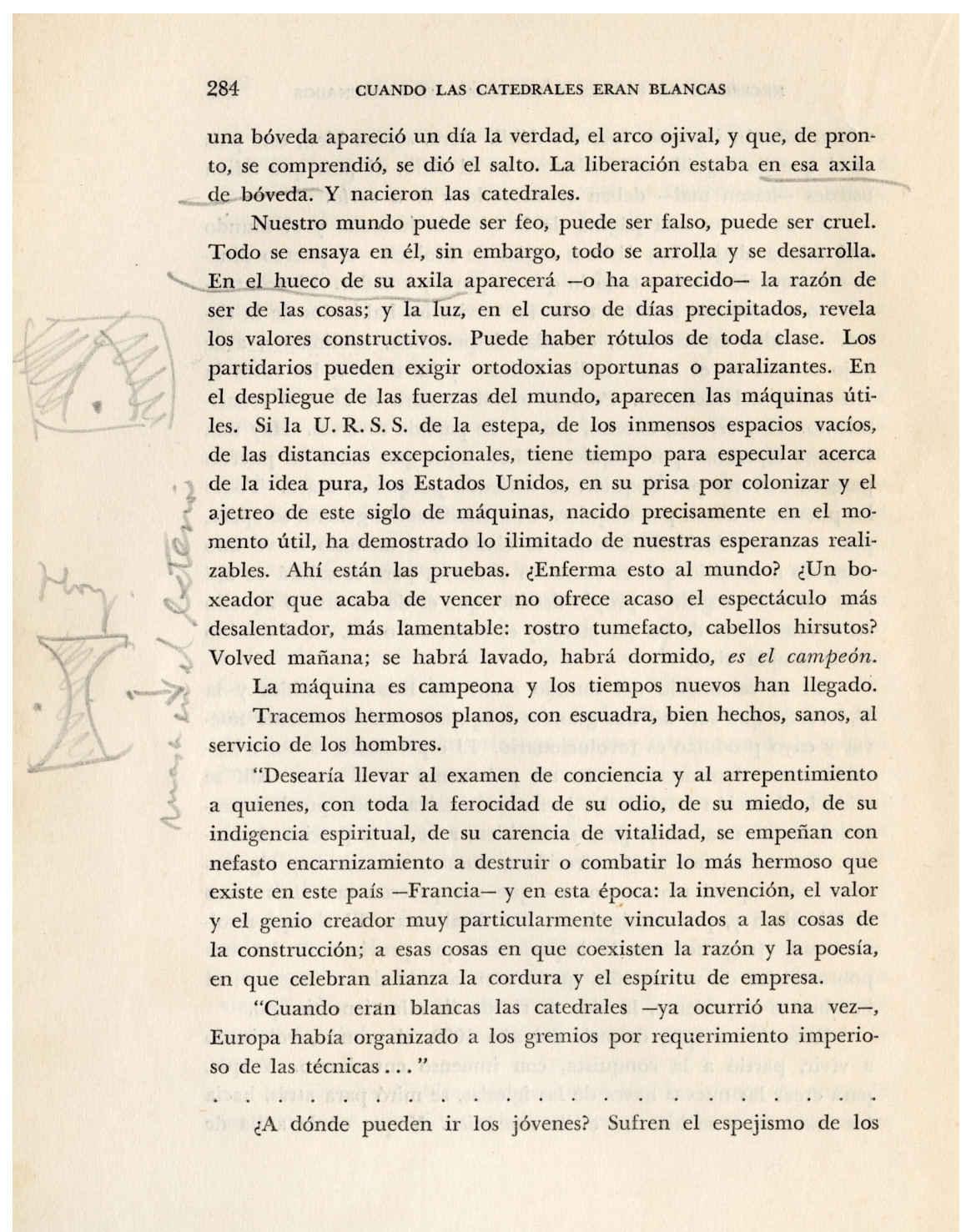

Fig. 7: Le Corbusier, Cuando las catedrales eran blancas. Anotación personal de Jorge Oteiza. AFMJO, FB-4652, Sign. 4362@ Jorge Oteiza $\odot$ Pilar Oteiza, A+V Agencia de Creadores Visuales, 2020
Añadimos a los dos anteriores La vivienda del hombre (Espasa Calpe, Madrid, 1945, FB-3880, Sign. 3694), de Le Corbusier y el ingeniero francés François de Pierrefeu, que registra el siguiente paralelismo: si para Le Corbusier el ser vivo es "un transformador de la energía solar", para Oteiza el artista es "un transformador de la energía divina” (p. 44); y Le Corbusier (Electa, Firenze, 1951, FB-3988, Sign. 3806), con diversos subrayados en la introducción del historiador del arte Jean Alazard, si bien lo más significativo resulta un dibujo de Oteiza en la portada interior que representa el perfil lateral de la característica unidad de habitación y la incidencia del sol en su trayectoria, relacionada con las láminas que ilustran el texto (Fig. 8).

Finalizamos este apartado con Le Corbusier (Gustavo Gili, Barcelona, 1985, FB-4642, Sign. 4349), del arquitecto suizo Willy Boesiger, que según nota manuscrita de Oteiza fue obsequio de "Jon a Oteitza. Madrid, enero 89". Debemos identificarlo con el escultor guipuzcoano Jon Iturrarte Artola (1948), quien meses atrás escribía a Oteiza para comunicarle su admisión e inicio de curso en el Instituto de Estética y Teoría de las Artes de la Universidad Autónoma de Madrid, manifestando igualmente su deseo de vincularse una vez concluidos sus estudios al Instituto de Investigaciones Estéticas promovido por el escultor oriotarra ${ }^{49}$. En sus páginas vuelve a interesarse por el Modulor con sus dos series que relaciona con "mi ley de los cambios" (pp. 88-89), a la vez que subraya los contenidos relativos a la capilla de Ronchamp (p. 120). Muy ilustrativa resulta la frase que anota junto a la lámina de la casa-taller del pintor francés Amédée Ozenfant en París, que muestra un espacio amplio, diáfano y bien iluminado, a propósito del cual dice: “yo en Irún” (p. 23), en alusión a su vivienda-taller compartida con Néstor Basterretxea.
49 “Carta de Jon Iturrarte a J. Oteiza”, Hernani, 12 de octubre de 1988. AFMJO, FD-93; “Carta de Jon Iturrarte a J. Oteiza”, Madrid, 26 de octubre de 1988. AFMJO, FD-9060. 


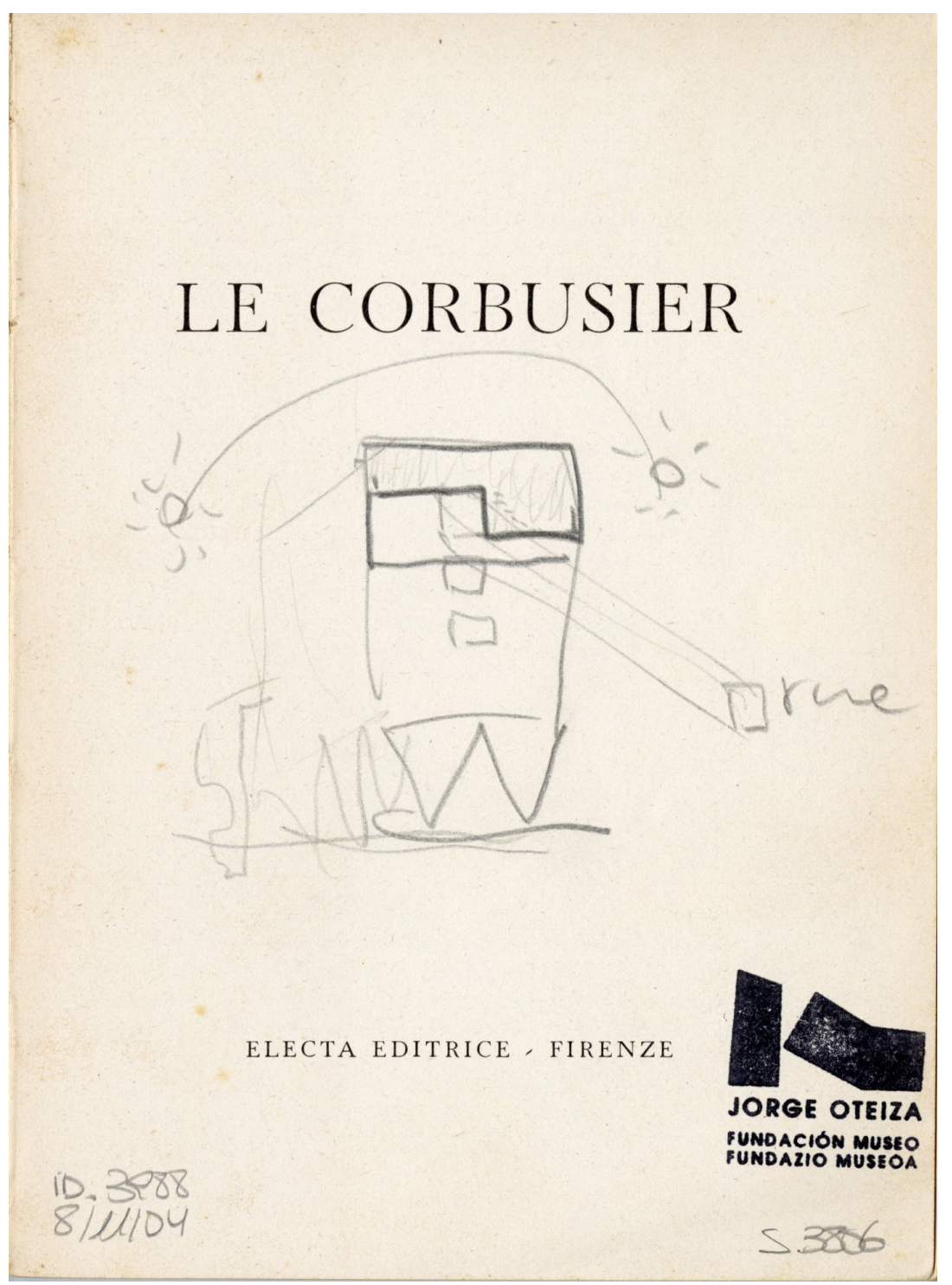

Fig. 8: Le Corbusier. Dibujo de Jorge Oteiza en la portada. AFMJO FB-3988, Sign. 3806 ๑ Jorge Oteiza () Pilar Oteiza, A+V Agencia de Creadores Visuales, 2020

\section{CONCLUSIONES}

Con más de 6.000 ejemplares, la biblioteca personal de Jorge Oteiza constituye un núcleo generador de conocimiento todavía por explorar. Sin duda debido a su faceta como teórico del arte, el escultor vasco concibe el libro no como un mero instrumento de consulta sino como una eficaz herramienta a través de la cual interactúa con sus autores en tiempo real y más allá de coordenadas espaciotemporales; sin duda, el libro es para Oteiza una auténtica "máquina del tiempo". Establece con arquitectos y artistas un enriquecedor diálogo por medio de subrayados, anotaciones y comentarios, y documentos manuscritos o mecanografiados, todos los cuales constituyen no un fin en sí mismos, sino un medio para avanzar en su propia reflexión y creación artística.

Todo este ingente caudal de información nos acerca a la plástica y pensamiento oteicianos de una manera directa, con el valor añadido de su inequívoca contextualización, por cuanto conocemos en muchos casos el momento exacto de su lectura y las ideas aparecen asociadas a la fuente original que las alumbró y desde la que partieron para, posteriormente, convertirse en escritos e incluso en esculturas con personalidad propia.

En nuestra aproximación a la biblioteca oteiciana, nos hemos decantado por una selección de autores y textos relacionados con la arquitectura contemporánea, que determinan en gran medida su propuesta estética a partir de la década de 1950. Reconoce su admiración y su deuda con Gaudí; expresa su desacuerdo con el pensamiento teórico de los arquitectos en la órbita de la Bauhaus, tanto con Gropius como con Mies van der Rohe, mostrando mayor afinidad con Hannes Meyer, con el que llega a equipararse; y manifiesta su proximidad a Le Corbusier, con quien le unen temas como la ocupación del espacio y el sistema de proporciones a partir de la sección áurea. En todos los casos, las conexiones entre el escultor y los arquitectos son constantes tanto a nivel teórico como de realización práctica, lo cual enriquece el diálogo virtual entre ellos.

No debemos pasar por alto que Oteiza adquirió y leyó la mayoría de los textos sobre arquitectura en los años cincuenta, período en el que se encuentra estrechamente vinculado a la arquitectura mediante su colaboración en diferentes proyectos en el País Vasco, Navarra, Madrid y Andalucía, sin olvidar la instalación del Pabellón Español en la Exposición Universal de Bruselas (1958) y el Monumento a José Batlle para Montevideo (1958-59), síntesis absoluta de arquitectura y escultura en colaboración con el arquitecto Roberto Puig. A ello se suma su asistencia a reuniones científicas como el I Congreso Internacional de Arte Abstracto (Santander, 1953), en el que además del propio Oteiza con 
una conferencia titulada "Escultura dinámica”, intervinieron arquitectos como Víctor d'Ors. De hecho, tenemos constancia de la carta enviada a la Revista Nacional de Arquitectura solicitando a su director que abriese una investigación acerca de la discusión mantenida con el arquitecto madrileño ${ }^{50}$.

Cuatro ideas clave se desprenden, a modo de síntesis, del "credo" oteiciano plasmado en los textos arquitectónicos: la arquitectura no solo satisface necesidades materiales, sino también y por encima de todo espirituales; en el concepto de educación se encuentra e fundamento de la comprensión estético-artística; el espacio es el elemento determinante y verdadero protagonista de la arquitectura (y no al revés); y basta la contemplación del espacio, del vacío, para sentir una emoción estética, tanto en arquitectura como en escultura. Ideas irrenunciables en la estética del escultor vasco. 


\section{BIBLIOGRAFÍA}

AGUIRRE MARTÍNEZ, G.: "Prometeo de Oteiza, un modelo para la desocupación espacial”, Ars Bilduma. Revista del Departamento de Historia del Arte y Música de la Universidad del País Vasco, 4, 2014, pp. 129-147. http://www.ehu.es/ojs/index.php/ars-bilduma/article/ view/7110 (Consultado el 20/08/2018).

ANDRÉS VIERGE, M.: Fernando Remacha. El compositor y su obra. Madrid, Instituto Complutense de Ciencias Musicales, 1998.

ANDRÉS VIERGE, M.: "Cuatro cartas de Fernando Remacha (1898-1984) a Jorge Oteiza (1908-2003)”, Revista Príncipe de Viana, 249, 2010, pp. 75-85.

ARGAN, G. C.: El concepto del espacio arquitectónico desde el Barroco a nuestros días. Buenos Aires, Nueva Visión, 1973.

ARNAIZ, A.: "Entre escultura y monumento. La estela del Padre Donostia para Agiña del escultor Jorge Oteiza”, Ondare. Cuadernos de Artes Plásticas y Monumentales, 25, 2006, pp. 305-325.

AZANZA LÓPEZ, J. J.: Crónica de un fracaso: Jorge Oteiza, Felipe IV y el VIII Centenario de San Sebastián (1950). Cuadernos del Museo Oteiza, 8. Alzuza, Fundación Museo Jorge Oteiza, 2013.

AZANZA LÓPEZ, J. J.: "Arte y estética en los Minutogramas de Jorge Oteiza”, Archivo Español de Arte, 361, 2018, pp. 48-51.

AZANZA LÓPEZ, J. J.: “Tratados, fuentes y textos teóricos del arte contemporáneo en la biblioteca personal del escultor Jorge Oteiza”, en ALONSO RUIZ, B., GÓMEZ MARTÍNEZ, J., POLO SÁNCHEZ, J. J., SAZATORNIL RUIZ, L. y VILLASEÑOR SEBASTIÁN

F. (eds.): La formación artística: creadores, historiadores, espectadores, Vol. 2. Santander, Universidad de Cantabria, 2018, pp. 1303-1316.

AZANZA LÓPEZ, J. J.: “Jorge Oteiza: el Barroco y Velázquez vistos desde Hispanoamérica”, en FERNÁNDEZ VALLE, M. Á., LÓPEZ CALDERÓN, C. y RODRÍGUEZ MOYA

I. (eds.): Pinceles y gubias del barroco iberoamericano. Santiago de Compostela y Sevilla, Andavira, 2019, pp. 405-426.
BADIOLA, TX.: Oteiza. Catálogo razonado de escultura. Alzuza, Fundación Museo Jorge Oteiza y Editorial Nerea, 2016.

CAMPO ARGOTE, M.: “Debako Arte Eskola. Una experiencia singular”. Ondare, 26, 2008 pp. 177-190.

DÍAZ EREÑO, G.: "Mi piedra de catalejo", en Exposición Oteiza 1935-1975. La casa del Ser. Valladolid, Caja de Burgos, 2010, s.p.

ETXEPARE IGIÑIZ, L. y GARCÍA NIETO, F.: Luis Vallet de Montano (1894-1982). Arquitecto de frontera. San Sebastián, COAVN Delegación de Gipuzkoa, 2015.

FERNÁNDEZ SALIDO, L. M.: Fernando Redón Huici, arquitecto. Pamplona, Gobierno de Navarra, 2006

FULLAONDO, J. D.: “Max Bill”, Nueva Forma, 92, 1973, p. 3.

GARCÍA ÁLVAREZ, C.: Gaudí. Símbolos del éxtasis. Madrid, Siruela, 2017.

GOLVANO GUTIÉRREZ, F.: Teoría estética, telos del arte y ley formal en Oteiza. Tentativas teóricas y praxis vanguardista en el contexto de la modernidad. Donostia-San Sebastián, Universidad del País Vasco, 2017. Tesis doctoral dirigida por M. Iriondo Aranguren y A. Casado da Rocha. http://hdl.handle.net/10810/24486 (Consultado el 22/10/2018).

GONZÁLEZ RIERA, B.: "El centro de Estudios del Museo Oteiza: descripción y reflexiones de una andadura”, Revisiones. Revista de crítica cultural, 7, 2011-2012, pp. 207-213.

LÓPEZ-BAHUT, E.: Jorge Oteiza y lo arquitectónico. De la estatua-masa al espacio urbano (1948-1960). A Coruña y Alzuza, Universidade da Coruña y Fundación Museo Jorge Oteiza, 2015.

LÓPEZ-BAHUT, E.: "De los collages y maquetas de vidrio de Oteiza al hormigón de Sáenz de Oíza”, VLC arquitectura. Research Journal, 3.1, 2016, pp. 55-83.

LÓPEZ-BAHUT, E.: "La lectura de Jorge Oteiza de Saber ver la Arquitectura a través de sus reflexiones dibujadas: influencia en sus trabajos arquitectónicos", EGA. Revista de expresión gráfica arquitectónica, 21, 28, 2016, pp. 114-125. 
MADERUELO RASO, J.: La idea del espacio en la arquitectura y el arte contemporáneos, 1960-1989. Madrid, Akal, 2008.

MAKAZAGA, L. y VADILLO, M.: La Escuela Experimental de Arte de Deba: una apertura hacia la vanguardia. Deba, Debako Ostolaza Kultur Elkartea, 2005.

MARTÍNEZ GORRIARÁN, C.: Jorge Oteiza, hacedor de vacíos. Madrid, Marcial Pons, 2011.

MATOS CASTAÑO, B.: Eduardo Chillida, arquitecto. Madrid, Universidad Politécnica de Madrid, 2015.

MONEO VALLÉS, R.: “Jorge de Oteiza, arquitecto”, Nueva Forma, 16, 1967, pp. 22-23.

MUÑOZ, M. T., "Prólogo. Arte, ciencia y mito", en OTEIZA, J.: Interpretación estética de la estatuaria megalítica americana. Carta a los artistas de América sobre el arte nuevo en la posguerra (coords. M. T. MUÑOZ, J. LIZASOAIN, y A. RUBIO). Alzuza, Fundación Museo Jorge Oteiza, 2007, pp. 13-68.

OTEIZA, J.: "Sobre el arte nuevo en la post-guerra: carta a los artistas de América", Revista de la Universidad del Cauca, 5, 1944, pp. 75-109.

OTEIZA, J.: Libro de los plagios. Pamplona, Pamiela, 1991.

OTEIZA, J.: Estética del huevo. Huevo y laberinto. Mentalidad vasca y laberinto. Pamplona, Pamiela, 1995.

Oteiza. Propósito experimental. Madrid, Fundación Caja de Pensiones, 1988.

Oteiza y la arquitectura: múltiple reflejo. Pamplona, Pamiela, 1996.

PLAZAOLA, J.: El arte y el hombre de hoy: apuntes para una filosofía del arte contemporáneo. Valladolid, Diputación Provincial de Valladolid, 1978.

RACIONERO GRAU, L.: Antoni Gaudí: el so de la pedra. Barcelona, Edicions 62, 2009.
SÁNCHEZ SIMÓN, I.: Oteiza y los nuevos paradigmas científicos. Alzuza, Fundación Museo Oteiza, 2012.

SAN MARTÍN, F. J. y MORAZA J. L.: Oteiza. Laboratorio de papeles. Alzuza, Fundación Museo Oteiza, 2006.

SARASOLA RUBIO, F.: “Oteiza, escultor y arquitecto. Análisis de unos croquis inédito para la Universidad Infantil Piloto e Ikastola Experimental en Elorrio. 1964”, Expresión Gráfica Arquitectónica, 26, 2015, pp. 100-109.

UBALDE MERINO, J.: La psicología entre la física y la ecología: la dialéctica de la energía como base de las ciencias. Santander, Jesús Ubalde Merino, 1973.

VADILLO, M. y MAKAZAGA, L.: Los proyectos educativos de Jorge Oteiza. El Instituto de Investigaciones Estéticas. Pamplona, Universidad Pública de Navarra, 2007.

ZEVI, B.: Saber ver la arquitectura. Buenos Aires, Poseidón, 1951.

ZUAZNABAR, G.: Piedra en el paisaje. Cuadernos del Museo Oteiza 2. Alzuza, Fundación Museo Jorge Oteiza, 2006. 